Portland State University

PDXScholar

Summer 9-30-2015

\title{
Gender Difference in Working Parents' Perceptions of Work/Family Conflict and the Role of Occupational Prestige
}

Heather Kirsten McCabe

Portland State University

Follow this and additional works at: https://pdxscholar.library.pdx.edu/open_access_etds

Part of the Family, Life Course, and Society Commons, and the Feminist, Gender, and Sexuality Studies Commons

Let us know how access to this document benefits you.

\section{Recommended Citation}

McCabe, Heather Kirsten, "Gender Difference in Working Parents' Perceptions of Work/Family Conflict and the Role of Occupational Prestige" (2015). Dissertations and Theses. Paper 2530.

https://doi.org/10.15760/etd.2527

This Thesis is brought to you for free and open access. It has been accepted for inclusion in Dissertations and Theses by an authorized administrator of PDXScholar. Please contact us if we can make this document more accessible: pdxscholar@pdx.edu. 
Gender Difference in Working Parents' Perceptions of Work/Family Conflict and the Role of Occupational Prestige

by

Heather Kirsten McCabe

A thesis submitted in partial fulfillment of the requirements for the degree of

\author{
Master of Arts \\ in \\ Sociology
}

Thesis Committee:

Maura Kelly, Chair

Hyeyoung Woo

Emily Shafer

Portland State University

2015 
(C) 2015 Heather Kirsten McCabe 


\begin{abstract}
As many Americans move away from the traditional homemaker-breadwinner family model, research on gender and work/family conflict has become increasingly important and the question of gender difference in experiences of work/family conflict continues to be relevant. While there is research that shows women tend to experience significantly greater work/family conflict than men, there are also studies that have shown little or no gender difference, and some that offer evidence that men are reporting more work/family conflict. This study contributes to the debate by examining gender and occupational prestige in regard to working parents' perceptions of work-to-family and family-to-work spillover, with a quantitative analysis of national probability sampled survey data from the General Social Survey's Quality of Working Life Module from the years 2006 and 2010. The findings indicate that fathers are reporting significantly more work/family conflict than mothers, and that higher prestige work is associated with greater work/family conflict, but occupational prestige has a gendered effect with work-to-family spillover and is found to be especially salient for fathers. Overall, this study demonstrates the need for policymakers and employers to acknowledge men's parenthood. The findings are evidence that there is a need for incentivized paternity leave initiatives in the United States, as well as more universal employee work/life programs that address the barriers to fathers utilizing family-accommodating benefits.
\end{abstract}




\section{DEDICATION}

To Jeff. 


\section{ACKNOWLEDGEMENTS}

I would like to acknowledge my thesis chair, Dr. Maura Kelly for her mentoring and facilitating, as well as my thesis committee members Dr. Hyeyoung Woo and Dr. Emily Shafer for their guidance during this process. I would also like to thank my fellow sociology graduate students for their sharing of ideas and feedback, my cohort in particular. 
TABLE OF CONTENTS

ABSTRACT

DEDICATION

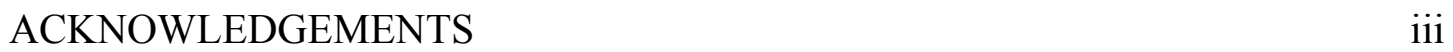

LIST OF TABLES v

LIST OF FIGURES vi

CHAPTER 1: INTRODUCTION

CHAPTER 2: LITERATURE REVIEW 6

$\begin{array}{ll}\text { CHAPTER 3: DATA AND METHODS } & 17\end{array}$

CHAPTER 4: RESULTS 26

CHAPTER 5: CONCLUSION 38

$\begin{array}{ll}\text { REFERENCES } & 51\end{array}$ 


\section{LIST OF TABLES}

TABLE 1: SAMPLE CHARACTERISTICS 27

TABLE 2: WORK HOURS AND PRESTIGE BY GENDER 28

TABLE 3: SPILLOVER BY GENDER 28

TABLE 4: ORDINAL LOGIT REGRESSION OF RELATIONSHIP BETWEEN WORK-TO-FAMILY SPILLOVER WITH GENDER AND JOB PRESTIGE AMONG EMPLOYED PARENTS N=1839

TABLE 5: ORDINAL LOGIT REGRESSION OF RELATIONSHIP BETWEEN WORK-TO-FAMILY SPILLOVER WITH GENDER AND JOB PRESTIGE AMONG EMPLOYED PARENTS N=1839

TABLE 6: ORDINAL LOGIT REGRESSION OF RELATIONSHIP BETWEEN FAMILY-WORK SPILLOVER WITH GENDER, AND JOB PRESTIGE AMONG EMPLOYED PARENTS N=1839 


\section{LIST OF FIGURES}

FIGURE 1: DISTRIBUTION OF SPILLOVER 28

FIGURE 2: LOG ODDS OF WORK-TO-FAMILY SPILLOVER 33 


\section{CHAPTER 1: INTRODUCTION}

This study seeks to explore the impact of occupational prestige on gender difference in individuals' experiences of work/family conflict using Risman's (2004; 1998) gender as structure theoretical framework. Kelly et al. (2014) refer to work/family conflict as "challenges managing paid work and non-work" (487). Work/family conflict is commonly referred to in directional terms, conceptualized by work/family researchers as negative work-to-family and family-to-work spillover, characterized by interference between the two realms of work and family (Frone 2006). Work-to-family spillover indicates that work life is spilling over to home life, and family-to-work spillover indicates that family life is spilling over to work life. Additionally, scholars argue that work/family conflict is more than just competing demands, there is a moral aspect (Gerson 2002; Blair-Loy 2003; Lamont 2002; Hennessy 2009; Garey 1999). Most previous studies have determined that women in particular are presented with conflicting cultural imperatives. Society presents working mothers with cultural schemas of "devotion to work" and "devotion to family" that put intensive mothering in conflict with work ethic (Blair-Loy 2003; 2001). However, men too are under pressure to be good providers, parents, and partners. Using data from the 2008 National Study of the Changing Workforce,

Aumann, Galinsky, and Matos (2011) have found that men's rates of experiencing work/family conflict are on the rise, and in recent years men's rates have even surpassed women's.

Work/family conflict is important to study because it is a mechanism that perpetuates both class and gender inequality. While men experience a fatherhood 
premium in contrast to their childless counterparts, women experience a motherhood penalty (Correll, Benard, and Paik 2007), especially mothers in low-income jobs (Anderson, Binder, and Krause 2003). In research on work/family conflict, scholars have operationalized class in a variety of ways, including, income, education, wealth, occupational categories (e.g. managerial), and occupational prestige (e.g. lower status and higher status jobs). The current study will pay special attention to one component of socio-economic status, occupational prestige. Although lower status jobs often have characteristics that produce work/family conflict such as rigid scheduling, minimal or no access to family benefits, and no paid leave, and higher status jobs typically offer resources to mitigate work/family conflict (Lambert and Waxman 2005; Blair-Loy and Wharton 2002; Swanberg, Pitt-Catsouphes, and Drescher-Burke 2005), higher status workers have been found to experience more work-to-family spillover than lower status workers (Schieman, Whitestone, and Van Gundy 2006). One reason for this could be that the flexibility offered to high status workers blurs the boundaries between work and family more. Another reason for this could be that resources like family benefits, although available to them are often not utilized by professional workers because of the nature of the work or culture of the workenvironment and the social pressure to live up to the ideal worker norm (Blair-Loy and Wharton 2002). Even though higher status workers tend to have more resources to reduce or alleviate work/family conflict, they also tend to have more job authority, which according to Schieman's concept of "stress of higher status" is associated with higher levels of work/family conflict. Schieman, Whitestone, and Van Gundy (2006) also found that those who are self-employed often experience more 
work/family conflict than others, despite their comparatively greater autonomy and schedule flexibility. This is an interesting contradiction and more empirical research is needed on work/family conflict and class to explore this idea (Bianchi and Milkie 2010).

It is important to look at both occupational prestige and gender because it is not a straightforward relationship between gender and work/family conflict since occupational prestige can mute or amplify gendered experience of work/family conflict. Little attention has been paid to how occupational prestige impacts gendered experiences of work/family conflict in quantitative work. Often, this is taken for granted and workers with low-level jobs are overlooked. Examining occupational prestige can contribute to better understandings about gender differences in work/family conflict because occupational prestige is related to social status position, resources, and job characteristics. Additionally, changes in the American family make this topic important to explore now. There has been a divergence from the traditional homemaker-breadwinner family model in the US with increases in numbers of breadwinner moms, stay at home fathers, single parents, and dual-earner households (Wang 2013; Livingston 2013; Livingston 2014; Parker 2013). Many of the quantitative studies on gender difference in experience of work/family conflict were based on survey data that came before these trends in family formation occurred. Since the ideal worker norm is based on the bread-winner/homemaker model, these changes to families could impact how work and family are managed by working parents. 
The proposed research takes a quantitative approach, using a nationally representative sample and predicts work/family conflict associated with gender and socio-economic status. Exploring gender difference quantitatively is important because there are some interesting results coming from qualitative studies on the intersection of gender and class in experiences of work/family conflict that can be tested to see if these are broad trends that are occurring. Most of the empirical research that examines gender differences in work/family conflict has focused on dual-earner married couples. The current study samples employed parents so to not exclude single-earner families or cohabitating couples who are parents. Guided by Risman's $(2004 ; 1998)$ gender as structure theoretical perspective, this research aims to advance understanding of gender difference in working parents' perceptions of work/family conflict, and how it varies by socio-economic status, specifically with an underexplored aspect, occupational prestige, to provide a look into more recent experiences of Americans.

\section{Research Questions and Hypotheses}

$\mathrm{RQ}_{1}$ : Is there a significant gender difference in working parents' perceptions of work/family conflict?

$\mathrm{H}_{1}$ : Overall among working parents there will be gender difference in perceptions of work/family conflict with fathers reporting higher levels of spillover than mothers.

$\mathrm{RQ}_{2}$ : Does occupational prestige moderate gender differences in perceptions of work/family conflict among working parents?

$\mathrm{H}_{2}$ : Occupational prestige moderates gender differences in perceptions of work/family conflict among working parents with increases in prestige having an increasing effect on mothers' spillover and a decreasing effect on fathers' spillover. 
Overview of Chapters

Chapter two discusses the theoretical framework of this study and explores existing literature on work/family conflict, reviewing antecedents of work/family conflict with particular attention to gender and socio-economic status. Chapter three describes this study's data and methods. Chapter four provides the results of the statistical analysis and an examination of the relationship between gender, occupational prestige, and work/family conflict. Chapter five discusses the research findings, describes how the findings contribute to the literature, addresses implications for practice and policy, discusses some limitations of this study, and provides recommendations for future research. 


\section{CHAPTER 2: LITERATURE REVIEW}

\section{Theoretical Perspectives}

This research is guided by Risman's $(2004 ; 1998)$ gender as structure perspective, a feminist theory that argues that gender is a social stratification structure that operates at the individual, interactional, and institutional level. Based on Giddens' (1984) structuration theory, Risman conceptualizes gender as a structure characterized by a dynamic relationship with the individuals it impacts; it is not a one-way relationship, individuals influence the gender structure just as the gender structure influences individuals. People's actions can either reinforce the gender structure by "doing gender" or make changes to it by "redoing gender." That is, individuals who perform gender according to traditional norms are reinforcing those norms, and individuals who contest those gender boundaries by performing gender differently are making changes to the established norms. Mothers' and fathers' experiences managing the demands of work and family are impacted by the gender structure via societal expectations that are embedded at the individual, interactional, and institutional levels which define what it means to be a worker, father, or mother. Thus, the gender structure can be reinforced or altered by the ways in which people carry out gender through mothering and fathering.

Historically, men's and women's roles have been different in work and family and today the gendered workplace and the gendered division of household labor contribute to maintaining these different societal expectations of mothers and fathers. The gendered workplace is perpetuated by workers being held to the ideal worker norm, which is the idea that work is organized based on the model of the 
unencumbered worker (Acker 1990). This may be especially important for men who hold high status jobs as Kelly, Ammons, and Moen (2010) suggest that for men who work in white-collar organizations that meeting the expectations of the ideal worker norm is a key way in which middle class men perform masculinity. The gender as structure theory would argue that hegemonic masculinity (Connell 1995) is embedded in organizations such as workplaces, and middle class men practicing masculinity in this way contributes to the gender and class hierarchy and to maintaining the ideal worker norm.

The cultural expectation for women who are parents is intensive mothering (Hays 1996). Women are expected to perform gender as parents by devoting themselves to being nurturers and caretakers. In contrast, men are expected to perform masculinity as parents by being providers. The results of these social pressures for fathers to conform to the breadwinner role and for mothers to conform to the caregiver role can be seen in the evidence from time diary studies which have found that fathers tend to work more hours than mothers and that mothers tend to perform the bulk of household responsibilities, especially childcare (Bianchi, Robinson, and Milkie 2006; Bianchi et al. 2000; Bielby and Bielby 1989; Biernat and Wortman 1991; Brines 1994; Tichenor 2005; Hochschild 1989; Coltrane 2000; Parker 2013; Jacobs and Green 1998).

But due to the socially constructed nature of gender categories, these role expectations are not static. Gender is created and recreated through daily experiences (West and Zimmerman 1987) and gender boundaries are negotiated (Gerson and Peiss 1985). Qualitative work on parenthood and gender has found that some 
individuals are redefining fatherhood and masculinity as well as motherhood and femininity, with class position having an influence on how parent roles are defined (Shows and Gerstel 2009; Hennessy 2009). West \& Zimmerman (1987) describe this as "redoing gender" which occurs at the interactional level of the gender structure, as Risman refers to this as "doing gender differently." By deviating from the established gender norms, individuals can influence the gender structure.

\section{Gender Difference}

Scholars have disputed gender difference in experiences of work/family conflict since spillover levels can vary depending on the groups being studied and the predictors can vary by gender, marital status, and family stage (Duxbury and Higgins 1991; McManus et al. 2002; Nomaguchi 2012; Erickson, Martinengo, and Hill 2010; Stevens et al. 2007; Bianchi and Milkie 2010).

Mixed evidence on gender difference in work/family conflict has been found in studies that compare multiple data sets (Eby et al. 2005; Jennifer Reid Keene and Quadagno 2004). There are some studies using nationally representative data that have found women experience higher levels of family-to-work spillover even among those who are married or living with a family member, adjusted by employment status (Keene and Reynolds 2005; Dilworth 2004), as well as with work-to-family spillover (Voydanoff 2005). There are studies using nationally representative data that found no gender difference in work/family conflict among employed adults (Mennino, Rubin, and Brayfield 2005; Grzywacz and Marks 2000), even when married (Voydanoff 1988), as well as for work/family balance (Milkie and Peltola 1999). 
This lack of consistency in findings for gender difference can be attributed to sampling differences from study to study (Bianchi and Milkie 2010; Byron 2005). One study found gender difference among White and Black parents, and gender similarity among White and Black non-parents even when controlling for occupational prestige (Roehling, Jarvis, and Swope 2005). In another study, gender differences in levels of family-to-work spillover were found for single parents, but not among married parents, with single mothers having the highest levels of familyto-work conflict in comparison to single fathers, married fathers, and married mothers (Nomaguchi 2012). A meta-analysis found that when more of a study's participants were parents, women tended to have more spillover than men, but when there were fewer parents in the sample, men tended to experience more spillover than women (Byron 2005). Another explanation for the lack of consistency in findings on gender difference in the literature could be attributed to the inconsistent operationalization of work/family conflict (Dilworth 2004). In Byron's (2005) meta-analysis, among the roughly 60 quantitative studies analyzed in which work/family conflict was the dependent variable, 30 different measures of work/family conflict were utilized. The gender effect can also vary depending on the direction of the spillover. Byron (2005) found that although the differences were small, men tended to have slightly more work-to-family spillover and women tended to have slightly more family-to-work spillover. Lastly, men and women's experiences of work/family conflict have changed over time. In a study of employed parents, fathers in dual-earner marriages were found to experience a significantly greater increase in work/family conflict from 1977 to 1997 than dual-earner mothers, and single earner mothers and fathers 
(Nomaguchi 2009). Descriptive statistics show that among dual-earner couples with children, fathers who report experiencing some or a lot of work/family conflict has risen from $35 \%$ in 1977 to $60 \%$ in 2008 , whereas mothers reporting some or a lot of work/family conflict has risen from 41\% in 1977 to $47 \%$ in 2008 (Aumann, Galinsky, and Matos 2011).

\section{Occupational Prestige}

There are some recent studies that highlight the utility of occupational prestige as a social status indicator (Fujishiro, Xu, and Gong 2010; Hoffmann and Jensen 2013; Nikolaev and Burns 2014). A literature review of recent research on socioeconomic status and family recommends that future quantitative research on SES and family examine the unique and combined contributions of three well supported indicators of social status: income, education, and occupational prestige (Conger, Conger, and Martin 2010). Conger, et al (2010) find that many studies favor using economic indicators of social status while ignoring education level and occupational prestige, which deserve more attention. Occupational prestige has been operationalized by scholars in various ways. Some studies have sorted respondents' into two occupational classifications, dummy coding for managerial/profession versus other or blue collar versus white collar (Dilworth 2004; Frone, Russell, and Lynne 1992; Keene and Quadagno 2004; Daphne et al. 2007; Roehling, Jarvis, and Swope 2005). One study has used ordinal measurements such as "executives," "midlevel professional," "administrative," "sales," "skilled," and "un- skilled" (Schieman, Whitestone, and Van Gundy 2006), while many use a continuous measure such as Bose and Rossi's (1983) NORC prestige scores (Fujishiro, Xu, and Gong 2010; 
Garland 2010; Helms-Erikson et al. 2000; Barnett and Marshall 1992; Nikolaev and Burns 2014; Xu and Leffler 1992), Treiman's Standard International Occupational Prestige Scale (Magnusson 2010), Duncan's SEI index (Kim et al. 2014), and the Wegener scale (Hoffman and Jensen 2013).

There is some research that suggests certain groups may tend to hold higher prestige occupations than others. When comparing mean occupational prestige scores of White, Black, Hispanic, and Asian men and women in a sample of employed adults from the 1980 US Census, Wu and Leffler (1992) found that men overall had higher prestige than women, but that race actually impacted job prestige more so than gender. Additionally, the predictors of job prestige can vary by gender. Using a sample of employed adults from the 1998 General Social Survey, Garland (2010) examined predictors of occupational prestige and found that for men, income and education were significant predictors. For women income, education, and being married were significant predictors, while part-time work was found to be negatively associated with prestige. Though education was significant for both men and women, it had more impact on prestige for women. Age, number of children, race, and region were not significant predictors for either men or women.

Previous research suggests that worker's experiences of work/family conflict may be influenced by occupational prestige. One study demonstrates that there are different predictors for spillover based on job prestige. A path analysis by Frone, Russell, and Cooper (1992) found with a sample of white collar and blue collar workers living with a partner and/or child in Erie County, New York that job involvement was significant in predicting work-to-family spillover for white collar 
workers, family distress was significant for blue collar workers, however work distress was related to family-to-work spillover for both groups. There are a few studies that show higher prestige workers experience more work/family conflict than lower prestige workers. In support of Schieman's "stress of high status" theory, Schieman, Whitestone, and Van Gundy (2006) found in a sample of employed adults living in Toronto Canada that the high status workers had significantly higher workto-home spillover than low status workers regardless of gender. Another study that found similar results is a study on full time dual-earner couples living in the Boston area in which higher occupational prestige work was associated with significantly more work/family conflict, but only for parents (Marshall and Barnett 1993). However, there is conflicting research that suggests occupational prestige may be not a significant factor in work/family conflict. When comparing men and women in separate samples of adults from dual-earner couples, MANOVA results found no significant differences between professional and nonprofessional workers in both directions of spillover (Stevens, Minnotte, and Kiger 2004).

Interaction of Gender and Socio-Economic Status

Shows and Gerstel (2009) explore classed fathering styles in their comparison of fathers who are working class and professional workers. They find that class position has an effect on the performance of masculinity through fathering styles. The working class fathers practiced a more "feminine" style of parenting than the professional fathers. They participated in the daily caretaking of children such as staying home with kids when they get sick, taking them to school or day care, or preparing meals for them. The professional fathers demonstrating family involvement 
to the community by going to children's events, and the researchers associate it with a "neo-traditional model of masculinity" where being a "good father" is being a good breadwinner. Shows and Gerstel use Deutsch's (2007) concept of "undoing gender" which "refers to social interactions that reduce gender difference," to help explain this (122). The working class fathers who practiced private fatherhood were considered to be "undoing gender," whereas the professional fathers who practiced public fatherhood were reinforcing traditional gender roles. This study demonstrates how occupational prestige can have an effect on the division of labor in the household. The professional men relied on their partners to take care of household duties and childrearing, while the working class men shared responsibilities for breadwinning and homemaking with their partner.

Weigt and Solomon (2008) also address the interaction of socio-economic status and gender in shaping working parents' management of work and family demands. They interviewed women who were university professors and women who held low-wage private sector job positions. For the women in this study, class privilege reduced work family conflict and moderated gendered experiences of work family conflict, but the women who were not privileged by class experienced more work family conflict and more gendered experiences of work family conflict. Job autonomy, schedule flexibility, paid leave, and childcare benefits also played a role in reducing conflict for the higher status workers.

Family and Work Characteristics

Family and work characteristics are important to consider when examining work/family conflict since these can shape how one manages work and family. 
Parental status is important to work/family conflict since the parenting experience is gendered, as mothers' and fathers' experiences managing the demands of work and family are impacted by the gender structure. Additionally, the gendered division of household labor is associated with parenting in the context of a couple, and the gendered the workplace can be associated with certain work characteristics.

Family characteristics can be associated with one's experience of work/family conflict, because for example, being married and having children living in the home have been found to be antecedents of spillover (Crouter 1984; Maume and Houston 2001; Roehling, Moen, and Batt 2003). Some studies have found that single parents experience more work/family conflict than married parents (Avison, Ali, and Walters 2007; Hertz 1999), while other studies show that marital status is not a significant factor in predicting high spillover levels in general, but it can vary by gender (Milkie et al. 2004; Nomaguchi 2012). Marital status has been found to have more of an effect on family-to-work spillover than it does on work-to-family spillover (Frone 2003). Low income is a family-to-work spillover predictor for single mothers, but not for married mothers (McManus et al. 2002). Nomaguchi (2012) finds that single mothers have more family-to-job conflict than single fathers, married mothers, and married fathers, and that predictors of spillover vary for each. Family stage is also a predictor of work/family conflict. Those with young children in the home tend to experience more negative spillover (Erickson, Martinengo, and Hill 2010) especially mothers (Stevens et al. 2007). Additionally, age and number of children living in the home has been found to predict more family-to-work spillover (Dilworth, 2004; Mennino et al., 2005; Stevens, Minnotte, and Kiger 2004). 
Work characteristics have been examined by many work/family researchers and tested as antecedents of spillover. Control over schedule and ability to take time off for family are associated with lower work/family conflict (Byron 2005; L. Golden et al. 2010; Hammer, Allen, and Grigsby 1997; Moen, Kelly, and Huang 2008; Roeters, Van Der Lippe, and Kluwer 2010; Galinsky, Bond, and Friedman 1996; Galinsky, Sakai, and Wigton 2011; Kossek, Lautsch, and Eaton 2006), and work flexibility has been found to reduce spillover especially for non-professional males (Stevens, Minnotte, and Kiger 2004).

Work hours have been found to be associated with higher work-to-family spillover (Grzywacz and Marks 2000; Kossek, Lautsch, and Eaton 2006; Gutek, Searle, and Klepa 1991; Batt and Valcour 2003; Berg, Kalleberg, and Appelbaum 2003; Major, Klein, and Ehrhart 2002; Prottas and Thompson 2006; Voydanoff 2004), and lacking autonomy is associated with higher levels of family-to-work spillover (Keene and Reynolds 2005). The more often a worker works from home, the more work-to-family conflict decreases, while family-to-work conflict increases (Golden, Veiga, and Simsek 2006).

In this chapter, I have discussed the gender as structure theory, which describes a reciprocal relationship between individuals and the gender structure at the individual, interactional, and institutional level. I summarized quantitative work on gender difference in experiences of work/family conflict, explored some family and work characteristics that have been found to be antecedents to work and family spillover, and discussed some qualitative studies that investigate intersections of gender and socio-economic status in working parents' experiences of work/family 
conflict. The current study aims to address the limited quantitative studies on the intersections of socio-economic status and gender. In the next chapter, I will describe the methodology used for studying the intersection of gender and socio-economic status and the impact of this on working parents' perceptions of work/family conflict. 


\section{CHAPTER 3: DATA AND METHODS}

To explore the impact of gender and occupational prestige on working parents' experiences of work family conflict, the current study analyzes survey data from the General Social Survey (GSS) using Ordinal Logistic Regression models to predict work-to-family and family-to-work spillover based on gender and occupational prestige while controlling for demographics, family characteristics, and work characteristics. To test the hypothesis that fathers tend to report significantly more spillover than mothers, the coefficient of the gender variable is assessed. To test the hypothesis that occupational prestige moderates the effect of gender on spillover with increases in prestige having an increasing effect on mothers' spillover and a decreasing effect on fathers' spillover, the current study assesses the coefficient of the interaction term that is the product of gender and occupational prestige.

Dataset

This study uses survey data from the GSS. The GSS is a national probability sample survey of U.S. English and Spanish speaking adults who are not in institutional living arrangements. The GSS has been conducted by computer-assisted personal interviews, face-to-face interviews, and telephone interviews, which typically last about 90 minutes on average. Conducted by the National Opinion Research Center (NORC) annually from 1972 to 1994 with the exception of 1979, 1981, and 1992, and conducted bi-annually onward. The response rate varies from year to year, but typically ranges from 71-79 percent. The core survey covers basic demographic information, work characteristics, and family composition, and there are also additional topic modules that vary from year to year that focus on particular 
subject areas. GSS data was used for this study because of the availability of variables of interest such as work-to-family and family-to-work spillover, and occupational prestige.

Sample

This study uses a subsample of the GSS, the "Quality of Working Life" module, which was carried out in 2002, 2006, and 2010. This module contains questions regarding the nature of respondents' workplace, job position, and about the intersection of spheres of home and work. Cases from this module were selected only from the years of 2006 and 2010 in order to reflect the most recent information. Data from the 2002 survey year was not included due to the age of the data. The sample was further limited to employed parents, and a small number of cases were excluded if they had missing values, resulting in a sample size of 1839 . These respondents include single parents as well as cohabiting and married parents to increase the sample size. Respondents in partnerships include both dual earner couples, and breadwinner-homemaker couples. Most of the respondents in partnerships are heterosexual couples. There is a small number of married same-gender couples, however the GSS excludes same-gender couples from the variable that measures nonmarried, cohabitating couples.

Dependent Variables

Work/family conflict is measured in the current study by respondents' perceptions of their experiences of work-to-family and family-to-work spillover. This is a subjective measure, but perceived work-life balance and work/family conflict are commonly used in work/family research. Although there are many studies that 
measure work/family conflict using an index, the necessary questions for this index are not used in the GSS. However, there have been similar single-item measures of work/family conflict used in previous studies (Dierdorff and Ellington 2008; Nomaguchi 2009; Voydanoff 1988; Winslow 2005).

Work-to-Family Spillover. The variable, WKVSFAM, describes the respondent's perception of how often his or her job interferes with family life. The survey asks respondents, "How often do the demands of your job interfere with your family life?" WKVSFAM is an ordinal variable, with the response categories: $1=$ Often, 2 = Sometimes, $3=$ Rarely, and $4=$ Never. WKVSFAM was reverse coded in order to reflect a larger value for more spillover and a smaller value for less spillover. The new variable WKFMSPVR, was coded: $1=$ Never, $2=$ Rarely, $3=$ Sometimes, and $4=$ Often .

Family-to-Work Spillover. The variable, FAMVSWK, captures the respondent's perception of how often the respondent's family life interferes with his or her job. The survey asks respondents, "How often do the demands of your family interfere with your work on the job?" FAMVSWK is an ordinal variable, with the response categories: $1=$ Often, $2=$ Sometimes, $3=$ Rarely, and $4=$ Never. This was reverse coded and labeled FMWKSPLVR in order to reflect a larger value for more spillover and a smaller value for less spillover: $1=$ Never, $2=$ Rarely, $3=$ Sometimes, and $4=$ Often. The reference category for the intercept is "often."

\section{Independent Variables}

Being a mother. The GSS variable, SEX, which indicates the respondent's gender, is coded as: $1=$ male, $2=$ female. Combined with parental status, a dummy 
variable MOTHER is coded as 1 for female with a child and 0 for father.

Occupational Prestige. The variable PRESTG80 indicates the respondents' occupational prestige on a scale of 10-90. The GSS uses the Census occupational and industrial classifications and matches them up with the NORC prestige score created by Nakao and Treas (1990) in a random sample survey in which respondents were asked to rate occupations.

Demographic Control Variables

Region. REGION in the GSS is coded as: $1=$ New England, $2=$ Middle Atlantic, $3=$ East North Central, $4=$ West North Central, $5=$ South Atlantic, $6=$ East South Central, $7=$ West South Central, $8=$ Mountain, $9=$ Pacific. This variable was recoded into NEWREGIONS: $1=$ Northeast, $2=$ Midwest, $3=$ South, and $4=$ West.

Race. RACE is coded as $1=$ White, $2=$ Black, and $3=$ Other. Race was reverse coded as $1=$ Other, $2=$ Black, and $3=$ White to NEWRACE in order to use White as the reference category in SPSS program.

Age. In the GSS, the age variable, AGE, is a continuous variable. The original GSS variable is used.

Education. The variable DEGREE measures the highest educational degree the respondent has obtained. The original coding from the GSS was used: $0=$ Less than high school, 1= High school, 2= Associate/Junior college, 3= Bachelor's, 4=Graduate.

Family Characteristics

Presence of young children. The BABIES variable indicates the number of children under the age of 6 living in the household. BABIES was recoded into the 
dummy variable ANYBABIES: 1 for those who have one or more children under age 6 in the household, and 0 for those who have no children under age 6 in the household.

Household type. HHTYPE1 is coded in the GSS: 1 = Married couple with no children, which is defined as " 2 or more adults with either respondent being married or two or more members being listed as married with no one under age 18." $2=$ Single parent, which is defined as " 1 adult and 1 or more members under age $18 . " 3=$ Other family, no children, which is defined as 2 or more adults with 2 nd or 3rd person listed related to head of household; no married couple and no household members under age 18." $4=$ Single adult which is defined as " 1 adult and no one under age 18." 5 = Cohabiting couple, no children, which is defined as " 2 adults of different genders not married nor related to each other. This category covers most, but not all, cohabiting couples. Excluded are cohabiting couples in which relationship and/or gender information was missing or households with three or more adults with at least one unrelated to the others. Also, same sex cohabiting couples are excluded." $6=$ Non-family, no children, which is defined as " 2 adults with 2 nd listed person unrelated to head and same gender as head and no one married, or with three or more adults with the 2 nd and 3 rd persons unrelated to head." $8=$ Unsure, no children, which is defined as " 2 or more adults, unmarried or with relationship and/or marital information unclear or conflicting, but with no one under age 18." $11=$ Married couple with child(ren), which is defined as "Number 1 with $1+$ members under age 18." $13=$ Other family with child(ren), which is defined as "Number 3 with $1+$ members under age 18." $15=$ Cohabiting couple with child(ren), which is defined as 
"Number 5 with $1+$ members under age 18." $16=$ Non-family with child(ren), which is defined as "Number 6 with $1+$ members under age 18." $18=$ Unsure with child(ren), which is defined as Number 8 with $1+$ members less than age 18." This variable was recoded into HOUSEHOLDTYPE, with the categories: 1= couple w/ minors, $2=$ single $\mathrm{w} /$ minors, $3=$ couple no minors, and $4=$ single no minors. In order to account for cohabitating couples, household type was used rather than a marital status variable. Other studies have used similar measures, such as a dummy variable for minors living in the household (Barnett 1994; Stevens, Minnotte, and Kiger 2004), and a couple/non-couple dummy variable (Blair-Loy and Wharton 2002; Mennino, Rubin, and Brayfield 2005; Moen, Kelly, and Huang 2008; Roeters, Van Der Lippe, and Kluwer 2010).

Financial strain

Financial strain. RINCBLLS is used as an indicator of financial strain. This variable is associated with the survey question, "Do you feel that the income from your job alone is enough to meet your family's usual monthly expenses and bills?" and the responses are coded as $1=$ yes, $2=$ no. This was recoded as financial strain with $1=$ yes and $0=$ no.

\section{Work Characteristics}

Work hours. The GSS variable HRS1 measures the number of hours the respondent worked the previous week. This continuous variable was recoded as an ordinal variable, WORKHOURS, which is coded in order to distinguish between those who work a standard full time workweek, those who work less than the 
standard workweek, and those who are working well over the standard workweek. It is coded as follows: $1=39$ hours or less, $2=40-49$ hours, $3=50$ hours or more.

Works from home regularly. The variable WRKHOME measures how often the respondent works at home as part of his or her job with the following response categories: $1=$ Never, $2=$ A few times a year, $3=$ About once a month, $4=$ About once a week, $5=$ More than once a week, $6=$ Worker works mainly at home. WRKHOME was recoded as a dummy variable to reflect whether or not the respondent works at home once a week or more. The new variable WRKATHOMEATLEASTWKLY is coded as $1=$ works once a week from home or more, $0=$ works from home less than once a week. Similar wording is used by Schieman and Glavin (2008).

Autonomy. WKFREEDM is the variable associated with the question, "I am given a lot of freedom to decide how to do my own work." The responses are coded 1 $=$ Very true, $2=$ Somewhat true, $3=$ Not too true, and $4=$ Not at all true (Golden et al. 2010; Mennino, Rubin, and Brayfield 2005).

Control over schedule. CHNGTME indicates how often respondents are allowed to change their starting and quitting times on a daily basis. The response categories are coded $1=$ Often, $2=$ Sometimes, $3=$ Rarely, and $4=$ Never (L. Golden et al. 2010). Some studies use a similar measure (Moen, Kelly, and Huang 2008; Roeters, Van Der Lippe, and Kluwer 2010; Schieman and Glavin 2008).

Ability to take time off for family. FAMWKOFF is associated with the question, "How hard is it to take time off during your work to take care of personal or family matters?" The responses are coded $1=$ Not at all hard, $2=$ Not too hard, $3=$ 
Somewhat hard, and 4 = Very hard (L. Golden et al. 2010; Mennino, Rubin, and Brayfield 2005).

Analytic Strategy

Analyses include descriptive statistics and Ordinal Logistic Regression analyses. First, frequencies, central tendencies, and cross tabulations were run to understand sample characteristics. Then, Ordinal Logistic Regression models are used to predict family-to-work and work-to-family spillover associated with gender and job prestige while controlling for basic demographics, family and work characteristics in order to explore the research questions: "Is there a significant gender difference in working parents' perceptions of work/family conflict?” and “Does occupational prestige moderate gender differences in perceptions of work/family conflict among working parents?" The dependent variables are ordinal and Ordinal Logistic Regression models allow the researcher to compare the often category against the sometimes, rarely, and never categories all at once. The ordinal interpretation is key to accurately addressing the proposed research question. The results of an Ordinal Logistic Regression analysis allow the researcher to determine the odds that fathers report higher levels of spillover than mothers. Other types of analysis such as MultiNomial Logistic Regression or Ordinary Least Squares Regression would not be appropriate for this study because they would ignore the ordered nature of the dependent variables.

Models were run for each of the dependent variables, FMWKSPLVR and WKFMSPVR, and main effects as well as interaction effects were examined. The first model includes only the gender variable to serve as a baseline for examining 
hypothesis 1 . Model 2 includes both main independent variables, gender and occupational prestige to determine the relationship between prestige, gender and spillover. Model 3 addresses hypothesis 2 by examining the interaction of gender and prestige with the addition of the product of prestige and gender. This interaction term tests whether the gender effect on spillover depends on occupational prestige. Model 4 tests whether the relationship holds when controlling for demographic factors. Model 5 controls for family characteristics. Model 6 adds financial strain, Model 7 adds hours worked, and Model 8 adds flexible work characteristics to the model to determine if the effect of gender and prestige on spillover is mediated by occupational characteristics. The final model adds an interaction variable gender $\mathrm{x}$ hours, the product of hours worked and gender, to see whether the effects of work hours on spillover differ for men and women.

In this chapter, I have described the dataset, sample, measures, and analytical strategy used for this research. The next chapter presents the results of the described analyses. 


\section{CHAPTER 4: RESULTS}

Descriptive Statistics

Table 1 shows descriptive statistics of this sample of working parents. The sample consists of slightly more women than men with $54.5 \%$ female and $45.5 \%$ male. A majority of the sample is White and works 40 hours or less. The mean age for this sample is 45.8. About half of the sample has at least a high school degree, and roughly a third have a bachelor's degree or higher. One fifth have at least one child under age 6 living in the household. A majority of the sample of parents currently had minors living at home with them, and about half of the respondents are coupled. Less than half of respondents say they have trouble paying the bills with their income. About a quarter of the sample works at home once a week or more. $27.7 \%$ of respondents work 50 or more hours per week, and $33.1 \%$ of respondents reported that they often had control over schedule. Most respondents reported that it was either very true or somewhat true that they had autonomy at their job, and claimed that it was either not too hard or not hard at all to take time off for family.

Respondents over the age of 65 are included in the sample since many workers are working past the typical retirement age of 65 , and older adults are not exempt from family responsibilities. For instance, it is common for grandparents to provide childcare to their grand children, and some grandparents are the legal guardians of their grand children. Lastly, some older adults are caregivers to spouses with health problems. 


\section{Table 1: Sample Characteristics}

Main Independent Variables

Female

Job prestige

Demographic Controls

Region

Northeast

Midwest

South

West

Race

White

Other

Black

Age

Level of education

Less than high schoo

High school degree

Associates degree

Bachelors degree

Graduate degree

Family Characteristics

Presence of children under age 6

Household type

Couple w/ minors

Couple no minors

Single w/ minors

Single no minors

Work Characteristics

Financial strain

Work hours

Part time (less than 40)

Full time (40-49)

Overwork $(50+)$

Works at home once a week or more

Autonomy

Very true

Somewhat true

Not too true

Not at all true

Control over schedule

Often

Sometimes

Rarely

Never

Ability to take time off for family

Not at all hard

Not too hard

Somewhat hard

Very hard

$\begin{array}{rrrrr}\mathbf{N} & \% & \text { range } & \text { mean } & \text { variance } \\ 1005 & 54.6 & & & \\ & & 17 \text { to } 86 & 44.43 & 189.585\end{array}$

$278 \quad 15.1$

$455 \quad 24.7$

$713 \quad 38.8$

$393 \quad 21.4$

$1383 \quad 75.2$

$180 \quad 9.8$

$276 \quad 15$

19 to $88 \quad 45.8 \quad 158.126$

$182 \quad 9.9$

$952 \quad 51.8$

$193 \quad 10.5$

$313-17$

$199 \quad 10.8$

$393 \quad 21.4$

$641 \quad 34.9$

$262 \quad 14.2$

$536 \quad 29.1$

$400 \quad 21.8$

$1075 \quad 58.5$

$540 \quad 29.4$

$790 \quad 43$

$509 \quad 27.7$

$453 \quad 24.6$

$1049 \quad 57$

$559 \quad 30.4$

$155 \quad 8.4$

$\begin{array}{ll}76 & 4.1\end{array}$

$608 \quad 33.1$

$357 \quad 19.4$

$268 \quad 14.6$

$606 \quad 33$

$762 \quad 41.4$

$584 \quad 31.8$

$310 \quad 16.9$

$183 \quad 10$ 
Table 2: Work Hours and Prestige by Gender

\begin{tabular}{llccccl} 
& \multicolumn{2}{c}{ Total } & \multicolumn{2}{c}{ Fathers } & \multicolumn{2}{c}{ Mothers } \\
\hline \multirow{3}{*}{ Work hours } & mean & SD & mean & SD & mean & SD \\
Prestige score & 41.43 & 14.87 & 45.46 & 14.36 & $38.09 * * *$ & 14.46 \\
\hline
\end{tabular}

***Significantly different from fathers at $\mathrm{p}<0.001$, two-tailed test

Figure 1: Distribution of Spillover

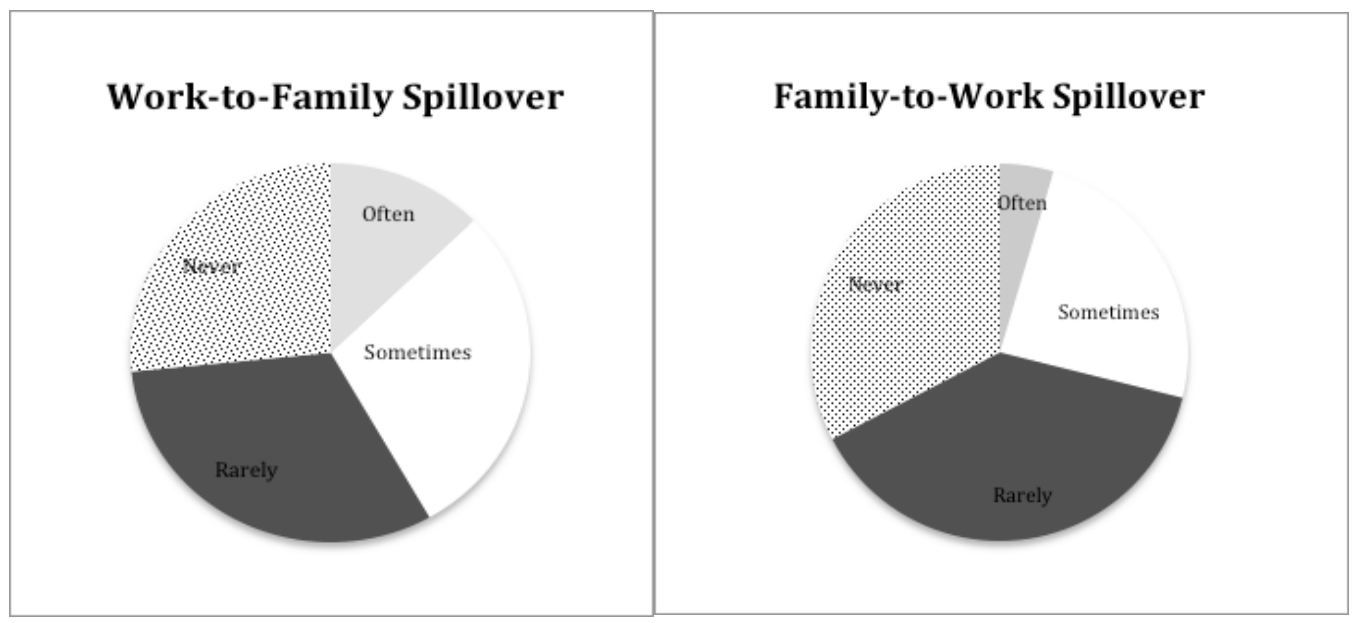

Table 3: Spillover by Gender

\begin{tabular}{lcccccc} 
& Total & \multicolumn{3}{c}{ Fathers } & \multicolumn{3}{c}{ Mothers } \\
Work-to-family spillover & $\mathbf{N}$ & $\mathbf{\%}$ & $\mathbf{N}$ & $\mathbf{\%}$ & $\mathbf{N}$ & \% \\
Often & 231 & 13 & 114 & 14 & 117 & 12 \\
Sometimes & 589 & 32 & 302 & 36 & 287 & 29 \\
Rarely & 584 & 32 & 261 & 31 & 323 & 32 \\
Never & 435 & 24 & 157 & 19 & 278 & 28
\end{tabular}

Family-to-work spillover

$\begin{array}{lrrrrrr}\text { Often } & 90 & 5 & 35 & 4 & 55 & 6 \\ \text { Sometimes } & 505 & 28 & 237 & 28 & 268 & 27 \\ \text { Rarely } & 738 & 40 & 343 & 41 & 395 & 39 \\ \text { Never } & 506 & 28 & 219 & 26 & 287 & 29\end{array}$


Table 2 shows the results of bivariate analysis by gender. Unexpectedly, the men and women in this sample had nearly identical mean prestige scores at 44.60 and 44.28. As expected, women tended to work less hours on average than men.

Figure 1 shows the percentages for responses to the questions regarding how often work and family interfere with each other, for both directions of spillover, "often" was the least common response: $12.6 \%$ for work-to-family spillover, and $4.9 \%$ for family-to-work spillover. There is some overlap with respondents who are reporting often spillover in both directions. 53 respondents, which is just $2.8 \%$ of the sample, chose the "often" category for both family-to-work and work-to-family spillover (not shown). Table 3 shows similar distributions in a comparison by gender. Regression Analyses

Results from Ordinal Logistic Regressions of work-to-family spillover by gender and occupational prestige are presented in Table 4. Model 1 serves as a baseline to test hypothesis 1 concerning gender difference. Captured through the odds ratio of the gender variable, the first model shows that without controlling for any other variables, mothers are $32 \%$ less likely than fathers to report a higher category of work-to-family spillover, and as the model is built, mothers become increasingly less likely. The odds ratio for mother $(0.24)$ in the final model demonstrates that even when controlling for demographic, family, and work characteristics, there remains a significant gender effect. Model 2 adds occupational prestige to the model. The odds ratio for prestige in Model 2 is 1.02, which means that for each increase in an occupational prestige score, a person is $2 \%$ more likely to report a higher category of work-to-family spillover. This reduces to $1 \%$ with the addition of controls to the 
Table 4: Ordinal Logit Regression of Relationship between Work-to-Family Spillover with

Gender and Job Prestige among Employed Parents $n=1839$

\begin{tabular}{|c|c|c|c|c|c|c|c|c|c|}
\hline Variable & Model 1 & Model 2 & Model 3 & Model 4 & Model 5 & Model 6 & Model 7 & Model 8 & Model 9 \\
\hline \multicolumn{10}{|l|}{ Main Independent Variables } \\
\hline mother (reference: father) & $0.68^{* * *}$ & $0.68 * * *$ & $0.43^{* *}$ & $0.39^{* *}$ & $0.38^{* *}$ & $0.36^{* *}$ & $0.43 * *$ & $0.37 * *$ & $0.24 * * *$ \\
\hline job prestige & & $1.02 * * *$ & $1.02 * * *$ & $1.02 * *$ & $1.02 * *$ & $1.02 * *$ & $1.01 *$ & $1.01^{*}$ & $1.01^{*}$ \\
\hline \multicolumn{10}{|l|}{ Interaction Term } \\
\hline mother $\mathrm{x}$ prestige & & & 0.99 & $0.99 *$ & $0.99^{*}$ & $0.99 *$ & $0.99 *$ & $0.98^{*}$ & $0.99 *$ \\
\hline \multicolumn{10}{|l|}{ Demographic Controls } \\
\hline \multicolumn{10}{|l|}{ region (reference: west) } \\
\hline northeast & & & & 0.80 & 0.79 & $0.78 \dagger$ & $0.77 \dagger$ & $0.78 \dagger$ & $0.76 \dagger$ \\
\hline midwest & & & & 1.07 & 1.09 & 1.09 & 1.06 & 1.05 & 1.05 \\
\hline south & & & & 1.03 & 1.05 & 1.05 & 1.00 & 0.97 & 0.97 \\
\hline \multicolumn{10}{|l|}{ race (reference: white) } \\
\hline other & & & & 0.83 & 0.85 & 0.84 & 0.86 & 0.84 & 0.84 \\
\hline black & & & & $0.50 * * *$ & $0.50 * * *$ & $0.51 * * *$ & $0.53 * * *$ & $0.58 * * *$ & $0.59 * * *$ \\
\hline age & & & & $0.98 * * *$ & $0.98 * * *$ & $0.98^{* * *}$ & $0.99 * *$ & $0.99^{*}$ & $0.99 *$ \\
\hline \multicolumn{10}{|c|}{ education (reference: graduate degree) } \\
\hline less than high school & & & & $0.48^{* *}$ & $0.49^{* *}$ & $0.48^{* * *}$ & $0.52 * *$ & $0.59^{*}$ & $0.60^{*}$ \\
\hline high school degree & & & & $0.57 * * *$ & $0.58^{* *}$ & $0.57^{* * *}$ & $0.58 * *$ & $0.66^{*}$ & $0.67 *$ \\
\hline associates degree & & & & $0.66^{*}$ & $0.66^{*}$ & $0.65^{*}$ & $0.70^{*}$ & 0.81 & 0.81 \\
\hline bachelors degree & & & & 0.91 & 0.90 & 0.89 & 0.92 & 1.00 & 0.99 \\
\hline \multicolumn{10}{|l|}{ Family Characteristics } \\
\hline presence of children under & nmy) & & & & $0.80 \dagger$ & $0.80 \dagger$ & 0.89 & 0.95 & 0.96 \\
\hline \multicolumn{10}{|c|}{ household type (reference: single no minors) } \\
\hline couple $\mathrm{w} /$ minors & & & & & $1.38^{*}$ & $1.35^{*}$ & $1.31^{*}$ & $1.29^{*}$ & $1.29 \dagger$ \\
\hline couple no minors & & & & & $1.45^{*}$ & $1.44^{*}$ & $1.44 \dagger$ & $1.46 \dagger$ & $1.47^{*}$ \\
\hline single $\mathrm{w} /$ minors & & & & & 0.94 & 0.92 & 0.90 & 0.89 & 0.89 \\
\hline \multicolumn{10}{|l|}{ Work Characteristics } \\
\hline financial strain (dummy) & & & & & & 1.13 & $1.32 * *$ & $1.27^{*}$ & $1.27 *$ \\
\hline \multicolumn{10}{|c|}{ hours worked last week (reference:overwork, over 50 hours) } \\
\hline partime (under 40) & & & & & & & $0.30 * * *$ & $0.39 * * *$ & $1.32 * * *$ \\
\hline fulltime $(40-49 \mathrm{hrs})$ & & & & & & & $0.47 * * *$ & $0.57^{* * *}$ & $0.43 * * *$ \\
\hline works at home once a week & dummy) & & & & & & & $1.50 * * *$ & $1.50^{* * *}$ \\
\hline \multicolumn{10}{|c|}{ autonomy (reference: Not at all true) } \\
\hline Very true & & & & & & & & 0.77 & 0.78 \\
\hline Somewhat true & & & & & & & & 0.77 & 0.78 \\
\hline Not too true & & & & & & & & 1.05 & 1.05 \\
\hline \multicolumn{10}{|c|}{ control over schedule (reference: Never) } \\
\hline Often & & & & & & & & $1.89 * * *$ & $1.91 * * *$ \\
\hline Sometimes & & & & & & & & $1.51^{* *}$ & $1.52^{* *}$ \\
\hline Rarely & & & & & & & & $1.41^{*}$ & $1.42 *$ \\
\hline \multicolumn{10}{|c|}{ ability to take time off for family (reference: Very hard) } \\
\hline Not at all hard & & & & & & & & $0.14 * * *$ & $0.15 * * *$ \\
\hline Not too hard & & & & & & & & $0.28 * * *$ & $0.28 * * *$ \\
\hline Somewhat hard & & & & & & & & $0.57 * *$ & $0.59 * *$ \\
\hline \multicolumn{10}{|c|}{ work hours $x$ gender interaction } \\
\hline part time $\mathrm{x}$ mother & & & & & & & & & 1.27 \\
\hline fulltime $\mathrm{x}$ mother & & & & & & & & & $1.61^{*}$ \\
\hline intercept 1 & $-1.393^{* * *}$ & $-0.545^{* * *}$ & $-0.800^{* * *}$ & $-2.874 * * *$ & $-2.583 * * *$ & $-2.540^{* * *}$ & $-2.995^{* * *}$ & $-4.057 * * *$ & $-3.880 * * *$ \\
\hline intercept 2 & 0.009 & $0.886^{* * *}$ & $0.633^{* *}$ & $-1.388 * * *$ & $-1.088^{*}$ & $-1.044^{*}$ & $-1.45^{* * *}$ & $-2.384 * * *$ & $-2.204 * * *$ \\
\hline intercept 3 & $1.743 * * *$ & $2.635^{* * *}$ & $2.382 * * *$ & 0.405 & $0.712 \dagger$ & $0.758 \dagger$ & 0.424 & -0.357 & -0.172 \\
\hline log likelihood & 44.15 & 1097.24 & 1094.38 & 4693.54 & 4716.99 & 4720.75 & 4632.97 & 4419.34 & 4414.59 \\
\hline
\end{tabular}

note: Only odds ratios are presented 
model, but overall as prestige increases, spillover also increases. Model 3 examines the interaction of gender and prestige with the addition of an interaction term and serves as a baseline to test hypothesis 2 , whether occupational prestige moderates gender differences. While the interaction term is not significant in model 3, it gains significance with the addition of other variables to the model. The significant interaction indicates that the size of the effect of gender on work-to-family spillover depends on job prestige for working parents. This result partially supports hypothesis 2, since occupational prestige moderates gender differences, meaning that level of occupational prestige impacts spillover differently for fathers and mothers. However it was expected that increases in prestige would have an increasing effect on mothers' spillover and a decreasing effect on fathers' spillover, and the results indicate the reverse. The significant interaction between occupational prestige and gender causes the slope of the regression line to decrease for mothers and increase for fathers.

Table 5: Ordinal Logit Regression of Relationship between Work-to-Family Spillover with Gender and Job Prestige among Employed Parents n=1839

\begin{tabular}{|c|c|c|c|c|c|c|c|c|}
\hline & Model 3 & Model 4 & Model 5 & Model 6 & Model 7 & Model 8 & Model 9 & \\
\hline variable & estimate & estimate & estimate & estimate & estimate & estimate & $\overline{\text { estimate }}$ & \\
\hline \multicolumn{9}{|l|}{ Main Independent Variables } \\
\hline mother (reference: father) & $-0.852 * *$ & $-0.942 * *$ & $-0.977 * *$ & $-1.016 * *$ & $-0.854 * *$ & $-1.036 * *$ & -1.414 & $* * *$ \\
\hline job prestige & $0.024 * * *$ & $0.015 * *$ & $0.015 * *$ & $0.015 * *$ & $0.012 *$ & $0.011 *$ & 0.010 & $*$ \\
\hline \multicolumn{9}{|l|}{ Interaction Term } \\
\hline mother $\mathrm{x}$ prestige & -0.010 & $-0.013 *$ & $-0.013 *$ & $-0.013 *$ & $-0.014 *$ & $-0.016 *$ & -0.015 & $*$ \\
\hline
\end{tabular}

Table 5 contains coefficients of the main variables in order to show the effect of the significant interaction between prestige and gender. The baseline model for predicting work-to-family spillover by occupational prestige and gender illustrates 
how the interaction impacts this relationship without controls. In model 3, the coefficient of prestige $(0.024)$ is the increase in logged odds per 1 unit increase in prestige score for fathers, and the coefficient for the interaction term is the additional effect of job prestige for mothers. This means that without accounting for controlling variables, higher job prestige levels seem to lead to higher odds of experiencing work-to-family spillover. However, this association differs by gender: For mothers, the higher levels of prestige appear to lead to lower levels of work-to-family spillover; but for fathers, the opposite pattern is found. This gendered association holds constant in Model 4, 5 and 6, where demographic controls, family characteristics, and financial strain are adjusted, respectively. Model 7 adds hours worked, and fathers' logged odds per 1 unit increase in prestige score increases by 0.012, while -0.014 is the additional effect for mothers. This means that when considering work hours, fathers continue to increase their odds of spillover as prestige increases and mothers appear to have decreasing levels of work-to-family spillover with increases in prestige. This holds true in Model 8 with the addition of flexible work characteristics to the model, and in Model 9 with the addition of the hours worked $\mathrm{x}$ gender interaction term. In comparison to the baseline model that does not include controls, when controlling for all factors fathers' odds become smaller and mothers' comparatively smaller odds turn into a decreasing pattern as prestige increases.

When including all controls, odds of high work-to-family spillover is consistently higher for fathers across all levels of occupational prestige. Fathers with high prestige jobs have the highest odds of work-to-family spillover, followed by 
fathers with low prestige work, and mothers with low prestige work. Mothers who are high prestige workers have the lowest odds of high work-to-family spillover. This finding supports Hypothesis 2 partially by demonstrating that the relationship between work-to-family spillover and gender varies by prestige.

The final model in the regression table for work-to-family spillover adds another interaction variable, the product of hours worked and gender. This model determines if the size of the effect of gender on work-to-family spillover depends on hours worked. There is a significant interaction between gender and fulltime work hours, which means that the effect of gender on work-to-family spillover depends on work hours for those who work fulltime hours. More specifically, there is a larger effect of working full time hours on fathers.

Figure 2: Log Odds of Work-to-Family Spillover

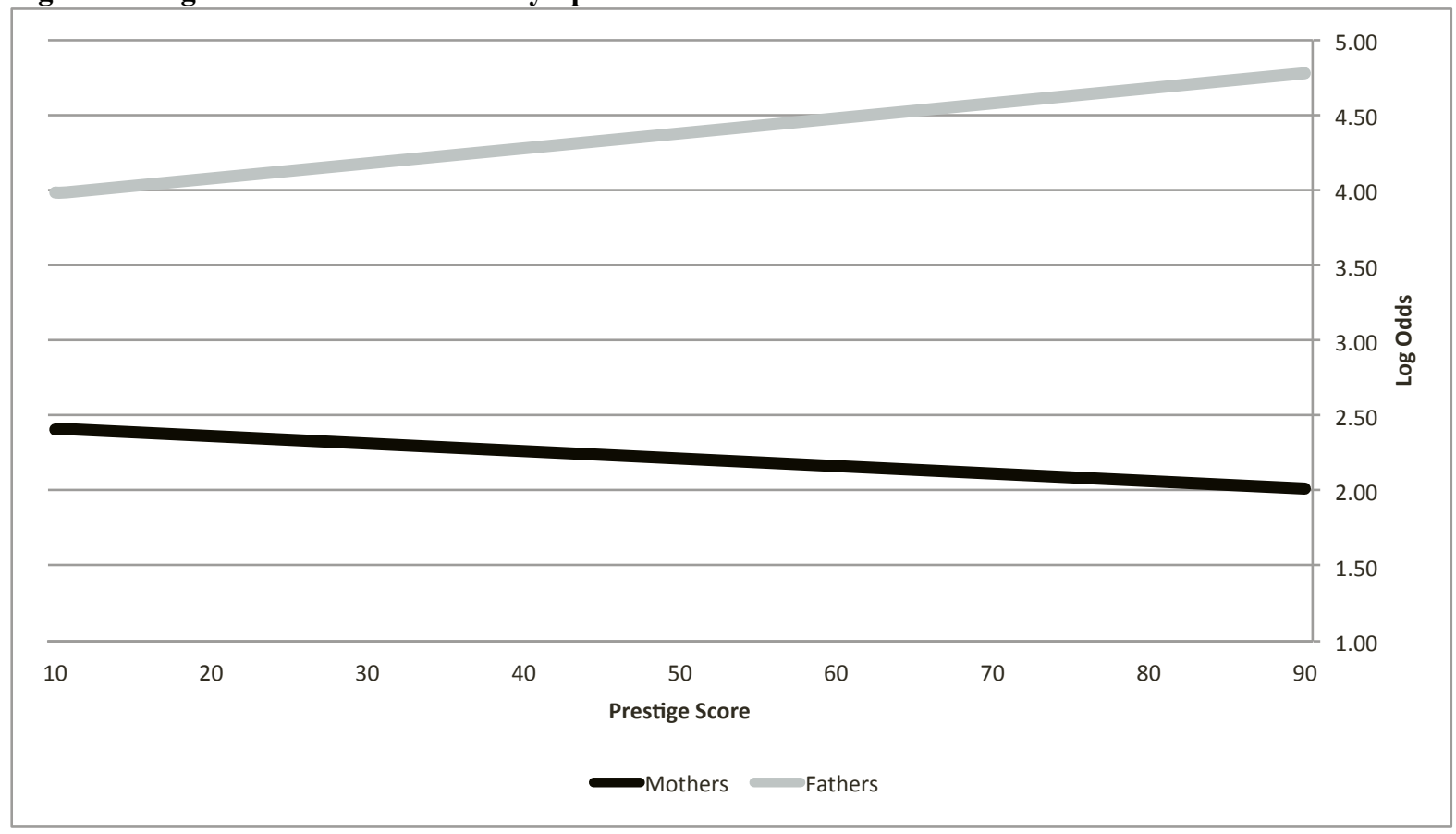

*Based on Mode1 9 
Figure 2 displays the log odds of work-to-family spillover by gender as prestige scores increase, showing how the gap increases between mothers' and fathers' log odds of spillover, with fathers' log odds increasing as prestige increases and mothers' log odds decreasing as prestige increases.

In the final model, among the controlling factors significantly associated with less work-to-family spillover were education, race, age, full-time work hours, the northeast region, and the ability to take time off for family. Education was most predictive for lower levels of educational attainment, with the lower the education level the lower the chances for spillover, but even a having a college degree means being less likely to experience work-to-family spillover. For race, being Black is associated with less work-to-family spillover. Among the factors associated with more work-to-family spillover were part-time work hours, financial strain, being coupled, telecommuting, and control over work schedule.

Table 6 presents results from the Ordinal Logistic Regression models that examine family-to-work spillover by gender and occupational prestige. Model 1 serves as a baseline to test hypothesis 1 . The odds ratio for gender in the first model (0.95) shows that without controlling for any other variables, mothers are 5\% less likely than fathers to report "often" family-to-work spillover, and as control variables are added, mothers become increasingly less likely. A significant gender effect in which fathers report significantly more family-to-work spillover than mothers is found when controlling for all factors, and hypothesis 1 is supported, but the coefficient for gender does not become significant until the final model with the addition of the interaction of hours worked and gender. When taking the relationship 
Table 6: Ordinal Logit Regression of Relationship between Family-Work Spillover with Gender, and Job Prestige Among Employed Parents n=1839

\begin{tabular}{|c|c|c|c|c|c|c|c|c|c|}
\hline Variable & Model 1 & Model 2 & Model 3 & Model 4 & Model 5 & Model 6 & Model 7 & Model 8 & Model 9 \\
\hline \multicolumn{10}{|l|}{ Main Independent Variables } \\
\hline mother (reference: father) & 0.95 & 0.96 & 0.88 & 0.79 & 0.79 & 0.71 & 0.74 & 0.67 & $0.49^{*}$ \\
\hline job prestige & & $1.02 * * *$ & $1.02 * * *$ & $1.01^{*}$ & $1.01^{*}$ & $1.01^{*}$ & $1.01 *$ & $1.01 *$ & $1.01^{*}$ \\
\hline \multicolumn{10}{|l|}{ Interaction Term } \\
\hline mother $\mathrm{x}$ prestige & & & 1.00 & 1.00 & 1.00 & 1.00 & 1.00 & 0.99 & 1.00 \\
\hline \multicolumn{10}{|l|}{ Demographic Controls } \\
\hline \multicolumn{10}{|l|}{ region (reference: west) } \\
\hline northeast & & & & 1.09 & 1.06 & 1.04 & 1.04 & 1.12 & 1.11 \\
\hline midwest & & & & 0.98 & 0.99 & 0.99 & 0.99 & 1.01 & 1.00 \\
\hline south & & & & 0.98 & 0.98 & 0.99 & 0.98 & 1.00 & 1.00 \\
\hline \multicolumn{10}{|l|}{ race (reference: white) } \\
\hline other & & & & 0.81 & 0.83 & 0.82 & 0.83 & 0.88 & 0.88 \\
\hline black & & & & $0.53 * * *$ & $0.53^{* * *}$ & $0.55^{* * *}$ & $0.56^{* * *}$ & $0.62 * * *$ & $0.62 * * *$ \\
\hline age & & & & $0.97 * * *$ & $0.98^{* * *}$ & $0.98 * * *$ & $0.98 * * *$ & $0.98 * * *$ & $0.98 * * *$ \\
\hline \multicolumn{10}{|c|}{ education (reference: graduate degree) } \\
\hline less than high school & & & & $0.33^{* * *}$ & $0.34^{* * *}$ & $0.32 * * *$ & $0.33^{* * *}$ & $0.40^{* * *}$ & $0.40^{* * *}$ \\
\hline high school degree & & & & $0.54 * * *$ & $0.54 * * *$ & $0.54 * * *$ & $0.54 * * *$ & $0.62 * *$ & $0.62 * *$ \\
\hline associates degree & & & & $0.57^{* *}$ & $0.58^{* *}$ & $0.56^{* *}$ & $0.57 * *$ & $0.62 *$ & $0.62 *$ \\
\hline bachelors degree & & & & $0.73 \dagger$ & $0.71^{*}$ & $0.71^{*}$ & $0.71^{*}$ & $0.72 \dagger$ & $0.72 \dagger$ \\
\hline \multicolumn{10}{|l|}{ Family Characteristics } \\
\hline presence of children under a & nmy) & & & & $0.74^{*}$ & $0.74 *$ & $0.75 *$ & $0.77 \dagger$ & $0.78^{\dagger}$ \\
\hline \multicolumn{10}{|c|}{ household type (reference: single no minors) } \\
\hline couple $\mathrm{w} /$ minors & & & & & $1.98^{* * *}$ & $1.87 * * *$ & $1.86^{* * *}$ & $1.82 * * *$ & $1.83^{* * *}$ \\
\hline couple no minors & & & & & $2.17^{* * *}$ & $2.14^{* * *}$ & $2.14^{* * *}$ & $2.10^{* * *}$ & $2.10^{* * *}$ \\
\hline single $\mathrm{w} /$ minors & & & & & $1.24 \dagger$ & 1.18 & 1.18 & 1.17 & 1.18 \\
\hline \multicolumn{10}{|l|}{ Work Characteristics } \\
\hline financial strain (dummy) & & & & & & $1.40^{* * *}$ & $1.42 * * *$ & $1.45 * * *$ & $1.44 * * *$ \\
\hline \multicolumn{10}{|c|}{ hours worked last week (reference:overwork, over 50 hours) } \\
\hline partime (under 40) & & & & & & & 0.85 & 0.95 & 0.81 \\
\hline fulltime $(40-49 \mathrm{hrs})$ & & & & & & & 0.89 & 1.01 & 0.84 \\
\hline works at home once a week & dummy) & & & & & & & $1.33^{*}$ & $1.33^{*}$ \\
\hline \multicolumn{10}{|c|}{ autonomy (reference: Not at all true) } \\
\hline Very true & & & & & & & & 0.72 & 0.73 \\
\hline Somewhat true & & & & & & & & 0.85 & 0.86 \\
\hline Not too true & & & & & & & & 0.72 & 0.73 \\
\hline \multicolumn{10}{|c|}{ control over schedule (reference: Never) } \\
\hline Often & & & & & & & & $2.11 * * *$ & $2.11^{* * *}$ \\
\hline Sometimes & & & & & & & & $1.38^{*}$ & $1.38^{*}$ \\
\hline Rarely & & & & & & & & $1.53^{* *}$ & $1.53 * *$ \\
\hline \multicolumn{10}{|c|}{ ability to take time off for family (reference: Very hard) } \\
\hline Not at all hard & & & & & & & & $0.66^{*}$ & $0.67 *$ \\
\hline Not too hard & & & & & & & & 0.89 & 0.91 \\
\hline Somewhat hard & & & & & & & & 1.20 & 1.22 \\
\hline \multicolumn{10}{|c|}{ work hours $x$ gender interaction } \\
\hline part time $\mathrm{x}$ mother & & & & & & & & & 1.33 \\
\hline fulltime $\mathrm{x}$ mother & & & & & & & & & 1.36 \\
\hline intercept 1 & $-0.995 * * *$ & -0.117 & -0.162 & $-2.63 * * *$ & $-1.986 * * *$ & $-1.862 * * *$ & $-1.915^{* * *}$ & $-1.889 * * *$ & $-1.744 * * *$ \\
\hline intercept 2 & $0.711^{* * *}$ & $1.621 * * *$ & $1.576^{* * *}$ & $-0.818^{*}$ & -0.148 & -0.016 & -0.067 & 0.011 & 0.158 \\
\hline intercept 3 & $2.941 * * *$ & $3.863 * * *$ & $3.818^{* * *}$ & $1.469^{* * *}$ & $2.151^{* * *}$ & $2.293 * * *$ & $2.241 * * *$ & $2.361 * * *$ & $2.509^{* * *}$ \\
\hline log likelihood & 41.86 & 942.45 & 942.36 & 4312.62 & 4317.04 & 4312.64 & 4314.28 & 4254.42 & 4252.28 \\
\hline
\end{tabular}


between hours and gender into account, there is a meaningful gender effect on familyto-work spillover but, since the coefficient for gender $\mathrm{x}$ work hours is not significant, there might not be a meaningful difference in the effect of hours worked on family-towork spillover for fathers in comparison to mothers. Model 2 adds occupational prestige to the model. The odds ratio for prestige in the baseline model is 1.02 , which means that for each increase in an occupational prestige score, a person is $2 \%$ more likely to report "often" family-to-work spillover than "never," "rarely," or "sometimes." This reduces to $1 \%$ with the addition of controls to the model, but overall as prestige increases, spillover also increases. The coefficient for prestige is significant in the final model, but loses some significance with the addition of controlling variables. The odds ratio for prestige in the final model is 1.01 , so for each increase in one's occupational prestige score, a person is $1 \%$ more likely to report high family-to-work and prestige with the addition of an interaction term and serves as a baseline to test hypothesis 2 , whether occupational prestige moderates gender differences. The coefficient of the interaction term for gender and prestige is not statistically significant, indicating that there is not a substantial difference in the effect of prestige on family-to-work spillover for fathers versus mothers, and hypotheses 2 is not supported by this result. Since there is not a significant interaction between prestige and gender in the regression models that predict family-to-work spillover, the regression line slopes are equal for fathers and mothers which means that high prestige fathers tend to report the highest levels of spillover, followed by high prestige mothers, low prestige fathers, and lastly low prestige mothers. 
The final model shows that significant controlling factors associated with less family-to-work spillover were education, race, age, and the ability to take time off for family, while financial strain, being coupled, control over work schedule, telecommuting, and having children in the household under the age of 6 were associated with more family-to-work spillover.

In this chapter I have described the sample characteristics, examined how the main variables of interest vary by gender, and interpreted the results of the Ordinal Logistic Regression models that estimate work-to-family and family-to-work spillover based on gender and occupational prestige. I address how these models fully support hypothesis 1 on gender difference and partially support hypothesis 2 on the moderating role of prestige on the gender effect. These results will be further discussed in the next chapter where I will consider the theoretical and empirical context of the results with a discussion on fathers' experiences managing work and family and the impact of occupational prestige on mothers' and fathers' perceptions of work-to-family spillover. I will also cover the significance of these findings to the work/family literature, how these findings impact future research, and what these findings mean for policy-makers and employers. 


\section{CHAPTER 5: CONCLUSION}

This research advances understanding of gender difference in working parents' perceptions of work/family conflict by examining how the gender effect varies by socio-economic status, specifically with an underexplored aspect, occupational prestige. The results support that working mothers and fathers are having significantly different experiences of work-to family and family-to-work spillover, and that working fathers' are reporting more spillover than working mothers. Fathers' experiences with managing work and family should be paid attention to by employers and policy makers. Also supported is that occupational prestige is an important factor to consider when examining gender differences in working parents' experiences of work-to-family spillover specifically. The findings of this study indicate that as prestige increases, family-to-work spillover increases regardless of gender and for work-to-family spillover gender matters as prestige increases. Fathers across all levels of occupational prestige reported higher levels of work-to-family spillover than mothers at any level of occupational prestige, and occupational prestige has more impact on fathers' work-to-family spillover than mothers'. This chapter includes a discussion of the contribution to the literature, recommendations for policy and practice, limitations, and suggestions for future research.

Findings

This study aims to address how social position impacts working parents' gendered experiences of work/family conflict based on survey data from the GSS from the years 2006 and 2010 using regression models to predict work-to-family and 
family-to-work spillover. The results of this study indicate a gender effect and that working fathers report more work/family conflict than working mothers, and even when controlling for demographic, family, and work characteristics, there remains a gender difference in perceptions of work-to-family spillover and family-to-work spillover among working parents. The gender as structure theoretical perspective would argue that the societal expectations of "being a man" and "being a good father" are changing. Additionally, occupational prestige tends to lead to higher levels of work-to-family spillover and this association is more salient for fathers. A high prestige occupation increases work-to-family spillover for fathers, while it decreases work-to-family spillover for mothers.

\section{Discussion}

Overall, there is a significant gender difference for both work-to-family and family-to-work spillover with men reporting higher levels of spillover when controlling for demographic, family, and work characteristics. Occupational prestige is a significant factor for both directions of spillover, with higher prestige associated with more interference. But only for work-to-family spillover does prestige moderate the gender effect, with prestige having a larger effect on fathers than mothers. These results fully support hypothesis 1 that "overall among working parents there will be gender difference in perceptions of work/family conflict with fathers reporting higher levels of spillover than mothers" and partially support hypothesis 2 that "occupational prestige moderates gender differences in perceptions of work/family conflict among working parents with increases in prestige having an increasing effect on mothers' spillover and a decreasing effect on fathers' spillover." 


\section{Fathers and Conflict}

What is interesting about these results is first that there is a significant gender difference and second, that fathers are more likely to report spillover than mothers. This may seem like a surprising result because the bulk of research on gender and work/family conflict supports that when a gender difference is found, women tend to report more conflict than men (Eby et al. 2005; Byron 2005). However, it should not be too surprising that men are reporting high levels of spillover because there is some research that suggests a shifting trend in men's experiences with managing work and family. A study on long-term trends in gendered experience of work/family conflict compared data over a 20 year period, from 1977 to 1997 , and found that overall all parents had significant increases in levels of conflict due to increases in education levels, work hours, and time pressure, but that fathers in dual-earner families experienced the greatest increases of work/family conflict in comparison to mothers and fathers of dual and single-earner families (Nomaguchi 2009). In addition to evidence of this upward trend, there is a small amount of quantitative research that provides evidence in support of men experiencing more conflict than women (Parasuraman and Simmers 2001; Aumann, Galinsky, and Matos 2011).

From a gender as structure theoretical perspective on work/family conflict, this could be attributed to the redoing of gender by fathers impacting the gender structure which can be seen in the shifting definition of fatherhood (Winslow 2005). Gender role expectations are subject to change over time, and fatherhood is undergoing a detraditionalization process, meaning that fathering is decreasingly modeled after the traditional idea of fatherhood (Williams 2008). The modern "ideal 
father" is an involved father (Ranson 2012). In recent years fathers have increased the amount of time they spend with their children (Sayer, Bianchi, and Robinson 2004). In this detraditionalization process, there lies tension between this idea of the new involved father and the requirements of traditional masculinity (McLaughlin and Muldoon 2014). When fathers were interviewed on the meaning they attach to fatherhood, many wanted to be different and felt they had to be different than previous generations of fathers in their relationship with their children and partners, but that despite changes in the meaning of a good father, performing the provider role remains central (Williams 2008). So if the definition of a "good father" has changed and men are wanting to spend more time with their children, but the expectation to perform the provider role has not changed, increased work/family conflict can be the result (Townsend 2002). The standard of the involved father is in conflict with the provider role, which is similar to the dilemma that mothers experienced when more women started to become increasingly involved in the workforce but the standard of intensive mothering remained. Another possibility for why fathers are reporting significantly more work/family conflict than mothers is that since these measures of spillover are based on perceptions of interference, men may be more likely to be sensitive to the ways that family and work interfere with each other and more likely to report it.

Additionally, since I controlled for couple status, this finding contributes to the literature that men report more work-to-family spillover than mothers regardless of whether a father is single or attached. Previous literature says that when men are 
found to report significantly higher levels of conflict than women that it is only true for men in dual-earner couples.

\section{The Role of Prestige}

Another interesting aspect of these findings on gender difference is the role of occupational prestige in predicting working parents' perceptions of work-to-family spillover. The significant interaction between prestige and gender for work-to-family spillover indicates that gender depends on prestige and prestige depends on gender in their effect on spillover, which suggests that a high prestige job has a larger impact on fathers' work-to-family spillover than it does for mothers. For example, there would be a greater gap in experiences of work-to-family spillover between a father who works as an executive, for instance, and a mother who held a similar position, in comparison to family-to-work spillover. This could be attributed to uneven utilization of family-friendly accommodations offered to white collar workers (Blair-Loy and Wharton 2002). White collar workers who request family-accommodations such as flextime, reduced hours, or a leave of absence for family reasons make their parent status salient in the workplace and flexibility stigma is triggered in distinct ways along gender and class lines (Williams, Blair-Loy, and Berdahl 2013).

The decreasing effect prestige has on mothers' work-to-family spillover occurs in later models starting with the addition of work hours, then continues with the addition of flexibility characteristics and the interaction of hours and gender. This indicates that work hours, control over schedule, ability to take time off for family, and autonomy matter for decreasing work-to-family spillover for mothers with higher prestige work, but not for fathers with high prestige work. Work might interfere with 
family less for mothers with high prestige work possibly because mothers with higher social-economic status have more resources than lower prestige mothers to outsource family responsibilities. It is possible that work interferes with family responsibilities more for high prestige fathers than low prestige fathers because adhering to the ideal worker norm is a key way in which fathers who hold high prestige jobs perform masculinity (Kelly et al. 2010) and the ideal worker norm requires workers to place their job responsibilities before family responsibilities. There is qualitative evidence in support of this finding that gendered experience of work/family conflict can differ by occupational prestige levels. Shows and Gerstal's (2009) findings support that "multiple masculinities" (Connell 1995) are created by differences in class position, suggesting that socio-economic status contributes to construction of masculinity. The existence of multiple masculinities helps to explain the different levels of spillover between higher and lower prestige fathers, and also contributes to contesting gender hegemony.

The current study's finding on the role of prestige supplements the findings of prior studies such as the Barnett and Marshall (1992) study that associated higher prestige work with high levels of work/family conflict for parents, and the Schieman, Whitestone, and Gundy (2006) finding that more prestige brings more conflict. However, in contrast to the "stress of high status" hypothesis that regardless of gender, high status workers have significantly more work-to-family spillover than low status workers, the current study suggests that gender does matter. One possible reason why these results conflict is that different measures of occupational prestige were used. In Schieman, Whitestone, and Gundy's (2006) study, social status position 
is measured by occupational categories of "executives," "midlevel professional," "administrative," "sales," "skilled," and "un-skilled." Another difference is that the current study samples parents, whereas Schieman, et al (2006) sample working adults.

Why is there a significant interaction between gender and prestige for workto-family spillover, but not for family-to-work spillover? This lack of significance indicates that the effect of occupational prestige on family-to-work spillover does not depend on gender, so when homelife interferes with worklife, there is not a gap in experience between high or low prestige mothers and fathers. The significance of the main effects indicate that occupational prestige is more relevant to family-to-work spillover than gender, which has a larger effect on work-to-family spillover, than family-to-work spillover. Additionally, having children under the age of 6 is significant for family-to-work, but not work-to-family spillover. This could also be tied to work hours, since this variable is more relevant to work-to-family than to family-to-work spillover, and since fathers tend to work more hours than mothers it would make sense that there would be a gap in experience by gender.

\section{Recommendations for policy and practice}

These findings highlight the importance of U.S. employers extending familyaccommodating benefits to men and women. Parental leave for example, is an area where employers should acknowledge working fathers. Paternity leave is rarely offered by employers or utilized by fathers in the US (Matos and Galinsky 2014), and one explanation for this is that men's parenthood is invisible in the workplace (Burnett et al. 2013). Under the Family and Medical Leave Act (FMLA), some US employers are required to make 12 weeks of unpaid leave available to both men and 
women, but often employers do not comply with their written policies and "parental leave" translates to maternity leave, and not paternity leave (Matos and Galinsky 2014). It has been found that access to family benefits does not determine use (BlairLoy and Wharton 2002), so technically in these workplaces in which FMLA is mandated, the leave is available equally regardless of gender, but in practice social pressure discourages fathers from taking paternity leave (Burnett et al. 2013). This brings about gaps in policy and practice. The gender as structure perspective would explain that the gender-neutral phrasing that appears in these formal policies only hides the gendered meaning of the policy which remains embedded in the logic (Williams 2000). Due to the way in which men are expected to perform masculinity, taking time off for family is something that is viewed as a mother-like action, a feminine style of parenting (Ridgeway 2011), and there are negative job consequences such as low performance evaluations for men who seek formal family accommodations (Vandello et al. 2013; Rudman and Mescher 2013; Reid 2015).

What some countries have had success with getting around these barriers to both fathers' access to and usage of paternity leave is by offering government supported incentivized paternity leave to working fathers. In Canada for instance, the Quebec Parental Insurance Program (QPIP) provides incentives to fathers through $55 \%$ to $70 \%$ income replacement and leave allotments that can only be used by fathers, rather than being eligible to be shared within a couple. Through the enactment of these policies, QPIP increased fathers' paternity leave participation by 51 percent, and also increased the average length of leave taken (Patnaik 2014). 
There is a similar barrier for fathers when it comes to other familyaccommodating workplace benefits, such as flexible schedules or telecommuting. There is the stigma associated with men utilizing these benefits because they are viewed as only something mothers do or uncommitted workers do (Ridgeway 2011; Kelly et al. 2010). Employers should promote these to workers as work/life benefits rather than work/family benefits because these benefits should be used by all workers. Designating these benefits for parents creates a hierarchy because not all workers have children and by viewing these more as family accommodations puts more value on childless workers. If flexible schedules and telecommuting is offered to and utilized by workers equally regardless of parental status or gender, this helps to reduce these hierarchies, for instance, by reducing social pressures for fathers to live up to the ideal worker norm. However, this has been tried before. The Results-Only Work Environment Initiative (ROWE) studied by Kelly et al. (2010) attempted to do this but the persistence of the ideal worker norm was a barrier to its long-term success. Kelly et al. (2010) found that worker's attitudes demonstrated the powerful hold that the ideal worker norm has in the work-place and that despite explicit efforts to remove the high value placed on things such as face-time, long hours, and visible busyness, it was difficult for workers to let go of this deeply ingrained culture.

Holding men to strict gender roles helps to maintain gender inequality. Acknowledging men's parenthood in the workplace and allowing men an actual equal chance to take on care work would be a positive step for gender equality, which is also positive for mothers. Fathers in heterosexual couples who take paternity leave tend to set a pattern of sharing care work with their partners that makes the division of 
household labor less gendered and more equitable over the long term (Harrington, Van Deusen, and Humberd 2011; Patnaik 2014). A more even sharing of care giving responsibilities could potentially lessen the motherhood penalty on women's wages. Acknowledging men's parenthood in the workplace is a positive step for fathers in heterosexual and queer couples, as well as single fathers, which is especially important because there are growing numbers of men in the US who are lone parents and stay-at-home parents. The rate of single fathers in the US has gone from $1 \%$ in 1960 to $8 \%$ in 2011 (Livingston 2013), and numbers of stay-at-home fathers in the US have risen from 1.1 million in 1989 to 2.0 million in 2012 (Livingston 2014). As of 2013, it is estimated that about 23\% of LGBT men are fathers (Street et al. 2015).

\section{Limitations}

One important caveat to mention is that this research uses subjective measures of work/family conflict and socio-economic status. This should be taken into consideration when making implications from these findings. In this study, work/family conflict is measured by respondents' perceptions of work-to-family and family-to-work interference and occupational prestige is measured by Americans' general perceptions of the prestige levels of particular occupations. Additionally, the accuracy of these ratings of occupations today are a potential limitation, since the GSS measure for occupational prestige was developed in the 1980's and some occupations have changed since then. Some jobs are not as prestigious now as they were 35 years ago. Lastly, the availability of all relevant data is a limitation because there are some variables that are relevant to work/family spillover that the GSS either 
does not include at all or does not include in the specific years of the quality of working life module, such as sense of control, role quality, or family life satisfaction.

\section{Future research}

Further research is needed to explore men's experiences managing work and family. For example, there are many quantitative studies on work/family conflict that have sampled only women, and a quantitative study that predicts work/family conflict using an all male sample would be useful to include in the work/family literature. Additionally, replicating this study using other recent national probability sampled datasets to see if fathers are reporting significantly more work/family conflict than mothers would help to verify this trend in men's work/family conflict. And since the measures for work/family conflict used in the current study are based on self-reported data, additional research using a less subjective measure of work/family conflict would be useful. More qualitative work that investigates why men are experiencing work/family conflict would also provide insight into these findings. In particular, it would be valuable to see more studies that focus on fathers with lower prestige occupations, since there already is a lot of literature that focuses on middle class white collar workers. Additionally, replicating this study with another dataset that includes LGBTQ cohabitating couples that are working parents would be beneficial.

The current study provides some evidence for one's social position impacting spillover differently for fathers and mothers. Perhaps it would be useful to extend this study to include income and educational attainment along with occupational prestige in order to examine the relationship with work/family conflict to all three components of SES, or to test whether these results still stand when substituting occupational 
prestige with other measures of social position. It would also be beneficial to try replicating this study using a more up to date measure of occupational prestige.

The current study examines the intersection of gender and class, but a truly intersectional approach that includes race would be an interesting direction. While this study includes race in the regression models as a controlling variable, the GSS race categories are simplistic, narrowing race down to three categories. Using a dataset that allows for more detail in the race variable would allow a researcher to examine intersections of class, gender, and race in working parents' experiences of work/family conflict.

Conclusion

Occupational prestige and gender are both significant factors impacting working parents' perceptions of work-to-family spillover and family-to-work spillover. Fathers are reporting significantly more work/family conflict than mothers, and what this study attributes this to is changes to the gender structure leading the traditional father role to collide with the new involved father role, causing men to feel more interference between work and family realms. When exploring the interaction of prestige and gender on work-to-family spillover, occupational prestige has a gendered effect. High prestige work has a larger increasing effect on fathers' work-to-family spillover, and a smaller decreasing effect on mothers' work-to-family spillover, while the gap in levels of work-to-family spillover between mothers and fathers with low prestige occupations is smaller.

This research contributes to the continuing debate over gender difference in the quantitative work/family conflict literature, and provides supportive evidence to 
qualitative work on fathers' experiences managing work and family. So far, the studies that have provided some evidence that men experience more conflict than women have limitations. The study by Parasuraman and Simmers (2001) uses MANACOVA to analyze a small non-representative sample of dual-earner couples. Analyses such as these assume a normal distribution, are limited in the number of control variables that can be included, and the sample does not allow for the results to be generalized to a greater population. The study by Aumann, Galinsky, and Matos (2011) use a representative sample of dual-earner couples, but they only refer to descriptive statistics. The current study reaches this conclusion using regression to predict work/family conflict based on gender and prestige while controlling for a number of factors using nationally representative data, which allows for more generalizable findings with fewer limitations. The findings on the role of prestige add a dimension of complexity to Schieman's "stress of high status" argument, and creates an interesting path for future research. Lastly, this study produces evidence to employers and policy makers that changes should be made in policy and practice regarding how we treat men's parenthood. 


\section{REFERENCES}

Acker, Joan. 1990. "Hierarchies, Jobs, Bodies: A Theory of Gendered Organizations." Gender \& Society 4 (2): 139-58.

Anderson, Deborah J., Melissa Binder, and Kate Krause. 2003. "The Motherhood Wage Penalty Revisited: Experience, Heterogeneity, Work Effort, and WorkSchedule Flexibility." Industrial \& Labor Relations Review 56 (2): 273-94. doi:10.1177/001979390305600204.

Aumann, Kerstin, Ellen Galinsky, and Kenneth Matos. 2011. "The New Male Mystique." National Study of the Changing Workforce. Families and Work Institute, New York.

Avison, William R., Jennifer Ali, and David Walters. 2007. "Family Structure, Stress, and Psychological Distress: A Demonstration of the Impact of Differential Exposure." Journal of Health and Social Behavior 48 (3): 301-17. doi:10.1177/002214650704800307.

Barnett, Rc. 1994. "Home-to-Work Spillover Revisited - a Study of Full-Time Employed Women." Journal of Marriage and the Family 56 (3): 647-56. doi: $10.2307 / 352875$.

Barnett, Rosalind C., and Nancy L. Marshall. 1992. "Men's Job and Partner Roles: Spillover Effects and Psychological Distress.” Sex Roles 27 (9-10): 455-72. doi:10.1007/BF00290003.

Batt, Rosemary, and P. Monique Valcour. 2003. "Human Resources Practices as Predictors of Work-Family Outcomes and Employee Turnover." Industrial Relations: A Journal of Economy and Society 42 (2): 189-220.

Berg, Peter, Arne L. Kalleberg, and Eileen Appelbaum. 2003. "Balancing Work and Family: The Role of High-Commitment Environments." Industrial Relations: A Journal of Economy and Society 42 (2): 168-88. doi:10.1111/1468232X.00286.

Bianchi, Suzanne M., and Melissa A. Milkie. 2010. "Work and Family Research in the First Decade of the 21st Century." Journal of Marriage \& Family 72 (3): 705-25. doi:10.1111/j.1741-3737.2010.00726.x.

Bianchi, Suzanne M., Melissa A. Milkie, Liana C. Sayer, and John P. Robinson. 2000. "Is Anyone Doing the Housework? Trends in the Gender Division of Household Labor." Social Forces 79 (1): 191-228. doi:10.1093/sf/79.1.191.

Bianchi, Suzanne M., John P. Robinson, and Melissa A. Milkie. 2006. "Changing Rhythms of American Family Life (American Sociological Association's Rose Series)." New York, NY: Russell Sage.

Bielby, William T., and Denise D. Bielby. 1989. "Family Ties: Balancing Commitments to Work and Family in Dual Earner Households." American Sociological Review 54 (5): 776-89. doi:10.2307/2117753.

Biernat, Monica, and Camille B. Wortman. 1991. "Sharing of Home Responsibilities between Professionally Employed Women and Their Husbands." Journal of Personality and Social Psychology 60 (6): 844-60. doi:10.1037/00223514.60.6.844. 
Blair-Loy, Mary. 2001. "Cultural Constructions Of Family Schemas The Case of Women Finance Executives." Gender \& Society 15 (5): 687-709. doi:10.1177/089124301015005004. 2003. Competing Devotions: Career and Family among Women Executives. Harvard University Press.

Blair-Loy, Mary, and Amy S. Wharton. 2002. "Employees' Use of Work-Family Policies and the Workplace Social Context." Social Forces 80 (3): 813-45. doi:10.1353/sof.2002.0002.

Brines, Julie. 1994. "Economic Dependency, Gender, and the Division of Labor at Home." American Journal of Sociology 100 (3): 652-88.

Burnett, Simon B., Caroline J. Gatrell, Cary L. Cooper, and Paul Sparrow. 2013. "Fathers at Work: A Ghost in the Organizational Machine." Gender Work and Organization 20 (6): 632-46. doi:10.1111/gwao.12000.

Byron, Kristin. 2005. "A Meta-Analytic Review of Work-family Conflict and Its Antecedents." Journal of Vocational Behavior 67 (2): 169-98. doi:10.1016/j.jvb.2004.08.009.

Coltrane, Scott. 2000. "Research on Household Labor: Modeling and Measuring the Social Embeddedness of Routine Family Work." Journal of Marriage and Family 62 (4): 1208-33. doi:10.1111/j.1741-3737.2000.01208.x.

Conger, Rand D., Katherine J. Conger, and Monica J. Martin. 2010. "Socioeconomic Status, Family Processes, and Individual Development." Journal of Marriage and Family 72 (3): 685-704. doi:10.1111/j.1741-3737.2010.00725.x.

Connel, Robert W. 1995. Masculinities. Berkeley. University of California Press.

Correll, Shelley J., Stephen Benard, and In Paik. 2007. "Getting a Job: Is There a Motherhood Penalty?” American Journal of Sociology 112 (5): 1297-1339. doi:10.1086/509519.

Crouter, Ann C. 1984. "Spillover from Family to Work: The Neglected Side of the Work-Family Interface." Human Relations 37 (6): 425-41.

Deutsch, Francine M. 2007. "Undoing Gender." Gender \& Society 21 (1): 106-27. doi:10.1177/0891243206293577.

Dierdorff, Erich C., and J. Kemp Ellington. 2008. 'It's the Nature of the Work: Examining Behavior-Based Sources of Work-Family Conflict across Occupations." Journal of Applied Psychology 93 (4): 883.

Dilworth, J. E. L. 2004. "Predictors of Negative Spillover from Family to Work." Journal of Family Issues 25 (2): 241-61. doi:10.1177/0192513X03257406.

Duxbury, Le, and Ca Higgins. 1991. "Gender Differences in Work-Family Conflict." Journal of Applied Psychology 76 (1): 60-74. doi:10.1037/0021-9010.76.1.60.

Duxbury, Linda, Christopher Higgins, and Catherine Lee. 1994. "Work-Family Conflict A Comparison by Gender, Family Type, and Perceived Control." Journal of Family Issues 15 (3): 449-66. doi:10.1177/019251394015003006.

Eby, L. T., W. J. Casper, A. Lockwood, C. Bordeaux, and A. Brinley. 2005. "Work and Family Research in IO/OB: Content Analysis and Review of the Literature (1980-2002)." Journal of Vocational Behavior 66 (1): 124-97. doi:10.1016/j.jvb.2003.11.003. 
Erickson, Jenet Jacob, Giuseppe Martinengo, and E Jeffrey Hill. 2010. "Putting Work and Family Experiences in Context: Differences by Family Life Stage." Human Relations 63 (7): 955-79. doi:10.1177/0018726709353138.

Frone, Michael R. 2003. "Work-Family Balance.” In Handbook of Occupational Health Psychology, edited by J. C. Quick and L. E. Tetrick, 143-62. Washington, DC, US: American Psychological Association.

—. 2006. "Work-Family Conflict." In Encyclopedia of Career Development, 868-70. Thousand Oaks, CA: SAGE Publications, Inc.

Frone, Michael R., Marcia Russell, and M. Lynne. 1992. "Antecedents and Outcomes of Work-Family Conflict: Testing a Model of the Work-Family Interface." Journal of Applied Psychology 77 (1): 65-78. doi:10.1037/0021-9010.77.1.65.

Fujishiro, Kaori, Jun Xu, and Fang Gong. 2010. "What Does 'occupation' Represent as an Indicator of Socioeconomic Status?: Exploring Occupational Prestige and Health." Social Science \& Medicine 71 (12): 2100-2107. doi:10.1016/j.socscimed.2010.09.026.

Galinsky, Ellen, James T. Bond, and Dana E. Friedman. 1996. "The Role of Employers in Addressing the Needs of Employed Parents." Journal of Social Issues 52 (3): 111-36.

Galinsky, Ellen, Kelly Sakai, and Tyler Wigton. 2011. "Workplace Flexibility: From Research to Action." The Future of Children 21 (2): 141-61.

Garey, Anita. 1999. Weaving Work Motherhood (Women In The Political Economy). Philadelphia, Pa, U.s.a.: Temple University Press. http://www.biblio.com/book/weaving-work-motherhood-women-politicaleconomy/d/620253983?aid=frg\&utm_source=google\&utm_medium=product \&utm_campaign $=$ feed-details.

Garland, Anna Nicole. 2010. "Prestige Inequality: The Effects of Family Status and Occupational Segregation." Thesis. https://beardocs.baylor.edu:8443/xmlui/handle/2104/7931.

Gerson, Judith M., and Kathy Peiss. 1985. "Boundaries, Negotiation, Consciousness: Reconceptualizing Gender Relations." Social Problems 32 (4): 317-31. doi:10.2307/800755.

Gerson, Kathleen. 2002. "Moral Dilemmas, Moral Strategies, and the Transformation of Gender Lessons from Two Generations of Work and Family Change." Gender \& Society 16 (1): 8-28. doi:10.1177/0891243202016001002.

Giddens, Anthony. 1984. The Constitution of Society: Outline of the Theory of Structuration. Univ of California Press. http://books.google.com.proxy.lib.pdx.edu/books?hl=en\&lr=\&id=x2bf4g9Z6 ZwC\&oi $=$ fnd\&pg=PR9\&dq=Giddens $+1984 \&$ ots $=\mathrm{jMVR}$ loyv5A\&sig=XHZ1r JXzszwn4tbIo5QV8Ruux4s.

Golden, Lonnie, Susan Lambert, Julia Henly, and Barbara Wiens-Tuers. 2010. "Working Time in the Employment Relationship: Perceived Control and Work-Life Balance." http://www.researchgate.net/publication/228309307_Working_Time_in_the Employment_Relationship_Perceived_Control_and_WorkLife_Balance/file/60b7d520cee477f92e.pdf. 
Golden, Timothy D., John F. Veiga, and Zeki Simsek. 2006. “Telecommuting's Differential Impact on Work-Family Conflict: Is There No Place like Home?" Journal of Applied Psychology 91 (6): 1340-50. doi:10.1037/00219010.91.6.1340.

Grzywacz, Joseph G., and Nadine F. Marks. 2000. "Reconceptualizing the Workfamily Interface: An Ecological Perspective on the Correlates of Positive and Negative Spillover between Work and Family." Journal of Occupational Health Psychology 5 (1): 111-26. doi:10.1037/1076-8998.5.1.111.

Gutek, Barbara A., Sabrina Searle, and Lilian Klepa. 1991. "Rational Versus Gender Role Explanations for Work-Family Conflict." Journal of Applied Psychology 76 (4): 560-68.

Hammer, Leslie B, Elizabeth Allen, and Tenora D Grigsby. 1997. "Work-Family Conflict in Dual-Earner Couples: Within-Individual and Crossover Effects of Work and Family." Journal of Vocational Behavior 50 (2): 185-203.

Harrington, Brad, Fred Van Deusen, and Beth Humberd. 2011. "The New Dad: Caring, Committed and Conflicted." Boston, MA: Boston College Center for Work \& Family.

Helms-Erikson, Heather, Jennifer L. Tanner, Ann C. Crouter, and Susan M. McHale. 2000. "Do Women's Provider-Role Attitudes Moderate the Links between Work and Family?" Journal of Family Psychology 14 (4): 658-70. doi:10.1037/0893-3200.14.4.658.

Hennessy, Judith. 2009. "Morality and Work-Family Conflict in the Lives of Poor and Low-Income Women.” Sociological Quarterly 50 (4): 557-80.

Hertz, Rosanna. 1999. "Working to Place Family at the Center of Life: Dual-Earner and Single-Parent Strategies." The ANNALS of the American Academy of Political and Social Science 562 (1): 16-31. doi:10.1177/000271629956200102.

Hochschild, Arlie Russell. 1989. The Second Shift: Working Parents and the Revolution at Home. New York, NY u.a.: Viking.

Hoffmann, Malte, and Uwe Jensen. 2013. Does Better Education Cause Higher Income?. HWWI.

http://www.hwwi.org/uploads/tx_wilpubdb/HWWI_Research_Paper_145_01. pdf.

Jacobs, Jerry A., and Kathleen Green. 1998. "Who Are the Overworked Americans?" Review of Social Economy 56 (4): 442-59. doi:10.1080/00346769800000044.

Keene, Jennifer Reid, and Jill Quadagno. 2004. "Predictors of Perceived WorkFamily Balance: Gender Difference or Gender Similarity?” Sociological Perspectives 47 (1): 1-23.

Keene, J. R., and J. R. Reynolds. 2005. "The Job Costs of Family Demands - Gender Differences in Negative Family-to-Work Spillover." Journal of Family Issues 26 (3): 275-99. doi:10.1177/0192513X04270219.

Kelly, Erin L., Samantha K. Ammons, Kelly Chermack, and Phyllis Moen. 2010. "Gendered Challenge, Gendered Response Confronting the Ideal Worker Norm in a White-Collar Organization." Gender \& Society 24 (3): 281-303. doi:10.1177/0891243210372073. 
Kelly, Erin L., Phyllis Moen, J. Michael Oakes, Wen Fan, Cassandra Okechukwu, Kelly D. Davis, Leslie B. Hammer, et al. 2014. "Changing Work and WorkFamily Conflict Evidence from the Work, Family, and Health Network." American Sociological Review, May, 0003122414531435. doi:10.1177/0003122414531435.

Kiley, Jocelyn. 2015. “It's Fathers' Day for Many American Men, Including 23\% of Those Who Are LGBT." Pew Research Center. Accessed April 20. http://www.pewresearch.org/fact-tank/2013/06/16/its-fathers-day-for-manyamerican-men-including-23-of-those-who-are-lgbt/.

Kim, Jeongeun, Jiyun Kim, Ozan Jaquette, and Michael N. Bastedo. 2014. "Institutional Stratification and the Postcollege Labor Market: Comparing Job Satisfaction and Prestige across Generations." The Journal of Higher Education 85 (6): 761-91. doi:10.1353/jhe.2014.0037.

Kossek, Ellen Ernst, Brenda A. Lautsch, and Susan C. Eaton. 2006. "Telecommuting, Control, and Boundary Management: Correlates of Policy Use and Practice, Job Control, and Work-family Effectiveness." Journal of Vocational Behavior 68 (2): 347-67.

Lambert, Susan, and Elaine Waxman. 2005. "Organizational Stratification: Distributing Opportunities for Work-Life Balance." Work and Life Integration: Organizational, Cultural, and Individual Perspectives. Mahwah, NJ: Erlbaum, 103-26.

Lamont, Michèle. 2002. The Dignity of Working Men: Morality and the Boundaries of Race, Class, and Immigration. New York, N.Y.; Cambridge, Mass.: Harvard University Press.

Livingston, Gretchen. 2013. "The Rise of Single Fathers." Pew Research Center's Social \& Demographic Trends Project. July 2. http://www.pewsocialtrends.org/2013/07/02/the-rise-of-single-fathers/. . 2014. "Growing Number of Dads Home with the Kids." Pew Research Center's Social \& Demographic Trends Project. June 5. http://www.pewsocialtrends.org/2014/06/05/growing-number-of-dads-homewith-the-kids/.

Magnusson, Charlotta. 2010. "Why Is There a Gender Wage Gap According to Occupational Prestige?” Acta Sociologica (Sage Publications, Ltd.) 53 (2): 99-117. doi:10.1177/0001699310365627.

Major, Virginia Smith, Katherine J. Klein, and Mark G. Ehrhart. 2002. "Work Time, Work Interference with Family, and Psychological Distress.” Journal of Applied Psychology 87 (3): 427.

Matos, K., and E. Galinsky. 2014. National Study of Employers. New York: Families and Work Institute.

Maume, David J., and Paula Houston. 2001. "Job Segregation and Gender Differences in Work-Family Spillover among White-Collar Workers." Journal of Family and Economic Issues 22 (2): 171-89.

McLaughlin, Katrina, and Orla Muldoon. 2014. "Father Identity, Involvement and Work-Family Balance: An In-Depth Interview Study." Journal of Community \& Applied Social Psychology, January, n/a - n/a. doi:10.1002/casp.2183. 
McManus, Kelly, Karen Korabik, Hazel M. Rosin, and E. Kevin Kelloway. 2002. "Employed Mothers and the Work-Family Interface: Does Family Structure Matter?" Human Relations 55 (11): 1295-1324. doi:10.1177/0018726702055011919.

Mennino, Sue Falter, Beth A. Rubin, and April Brayfield. 2005. "Home-To-Job And Job-To-Home Spillover: The Impact of Company Policies and Workplace Culture.” Sociological Quarterly 46 (1): 107-35. doi:10.1111/j.15338525.2005.00006.x.

Milkie, Melissa A., Marybeth J. Mattingly, Kei M. Nomaguchi, Suzanne M. Bianchi, and John P. Robinson. 2004. "The Time Squeeze: Parental Statuses and Feelings About Time With Children.” Journal of Marriage and Family 66 (3): 739-61. doi:10.1111/j.0022-2445.2004.00050.x.

Milkie, Melissa A., and Pia Peltola. 1999. "Playing All the Roles: Gender and the Work-Family Balancing Act." Journal of Marriage and the Family 61 (2): 476-90.

Moen, Phyllis, Erin Kelly, and Qinlei Huang. 2008. "Work, Family and Life-Course Fit." Journal of Vocational Behavior 73 (3): 414-25. doi:10.1016/j.jvb.2008.08.002.

Nakao, Keiko, and Judith Treas. 1990. Computing 1989 Occupational Prestige Scores. 70. National Opinion Research Center Chicago. http://publicdata.norc.org:41000/gss/Documents/Reports/Methodological_Rep orts/Mr070.pdf.

Nikolaev, Boris, and Ainslee Burns. 2014. "Intergenerational Mobility and Subjective Well-being-Evidence from the General Social Survey." Journal of Behavioral and Experimental Economics 53 (December): 82-96. doi:10.1016/j.socec.2014.08.005.

Nomaguchi, Kei M. 2009. "Change in Work-Family Conflict Among Employed Parents Between 1977 and 1997." Journal of Marriage and Family 71 (1): 15-32. doi:10.1111/j.1741-3737.2008.00577.x.

—. 2012. "Marital Status, Gender, and Home-to-Job Conflict Among Employed Parents." Journal of Family Issues 33 (3): 271-94. doi:10.1177/0192513X11415613.

Parasuraman, S., and C. A. Simmers. 2001. "Type of Employment, Work-Family Conflict and Well-Being: A Comparative Study.” Journal of Organizational Behavior 22 (5): 551-68. doi:10.1002/job.102.

Parker, Kim. 2013. "Modern Parenthood." Pew Research Center's Social \& Demographic Trends Project. March 14.

http://www.pewsocialtrends.org/2013/03/14/modern-parenthood-roles-ofmoms-and-dads-converge-as-they-balance-work-and-family/.

Patnaik, Ankita. 2014. "Reserving Time for Daddy: The Short and Long-Run Consequences of Fathers' Quotas." Available at SSRN 2475970. http://papers.ssrn.com.proxy.lib.pdx.edu/sol3/papers.cfm?abstract_id $=247597$ 0 .

Prottas, David J., and Cynthia A. Thompson. 2006. "Stress, Satisfaction, and the Work-Family Interface: A Comparison of Self-Employed Business Owners, 
Independents, and Organizational Employees." Journal of Occupational Health Psychology 11 (4): 366.

Ranson, Gillian. 2012. "Men, Paid Employment and Family Responsibilities:

Conceptualizing the 'Working Father."' Gender Work and Organization 19

(6): 741-61. doi:10.1111/j.1468-0432.2011.00549.x.

Reid, Erin. 2015. "Embracing, Passing, Revealing, and the Ideal Worker Image: How

People Navigate Expected and Experienced Professional Identities."

Organization Science.

http://pubsonline.informs.org.proxy.lib.pdx.edu/doi/10.1287/orsc.2015.0975.

Ridgeway, Cecilia L. 2011. Framed by Gender : How Gender Inequality Persists in the Modern World. Oxford England; New York, NY: Oxford University Press.

Risman, Barbara. 1998. Gender Vertigo. New Haven, CT: Yale University Press.

Risman, Barbara J. 2004. "Gender as a Social Structure Theory Wrestling with Activism." Gender \& Society 18 (4): 429-50.

Roehling, P. V., L. H. Jarvis, and H. E. Swope. 2005. "Variations in Negative WorkFamily Spillover among White, Black, and Hispanic American Men and Women - Does Ethnicity Matter?” Journal of Family Issues 26 (6): 840-65. doi:10.1177/0192513X05277552.

Roehling, P. V., P. Moen, and R. Batt. 2003. "It's about Time: Couples and Career."

Roeters, Anne, Tanja Van Der Lippe, and Esther S. Kluwer. 2010. "Work

Characteristics and Parent-Child Relationship Quality: The Mediating Role of Temporal Involvement." Journal of Marriage and Family 72 (5): 1317-28. doi:10.1111/j.1741-3737.2010.00767.x.

Rudman, Laurie A., and Kris Mescher. 2013. "Penalizing Men Who Request a Family Leave: Is Flexibility Stigma a Femininity Stigma?" Journal of Social Issues 69 (2): 322-40. doi:10.1111/josi.12017.

Sayer, Liana C., Suzanne M. Bianchi, and John P. Robinson. 2004. “Are Parents Investing Less in Children? Trends in Mothers' and Fathers' Time with Children." American Journal of Sociology 110 (1): 1-43. doi:10.1086/386270.

Schieman, Scott, and Paul Glavin. 2008. "Trouble at the Border?: Gender, Flexibility at Work, and the Work-Home Interface." Social Problems 55 (4): 590-611. doi:10.1525/sp.2008.55.4.590.

Schieman, Scott, Yuko Kurashina Whitestone, and Karen Van Gundy. 2006. "The Nature of Work and the Stress of Higher Status." Journal of Health and Social Behavior 47 (3): 242-57.

Shows, Carla, and Naomi Gerstel. 2009. "Fathering, Class, And Gender A Comparison of Physicians and Emergency Medical Technicians." Gender \& Society 23 (2): 161-87. doi:10.1177/0891243209333872.

Stevens, Daphne Pedersen, Krista Lynn Minnotte, Susan E. Mannon, and Gary Kiger. 2007. "Examining the 'Neglected Side of the Work-Family Interface' Antecedents of Positive and Negative Family-to-Work Spillover." Journal of Family Issues 28 (2): 242-62. doi:10.1177/0192513X06294548.

Stevens, D. P., K. L. Minnotte, and G. Kiger. 2004. "Differences in Work-to-Family and Family to-Work Spillover among Professional and Nonprofessional 
Workers." Sociological Spectrum 24 (5): 535-51.

doi:10.1080/02732170490483532.

Street, 1615 L., NW, Suite 700 Washington, and DC 200362024194300 | Main 202 4194349 | Fax 2024194372 | Media Inquiries. 2015. "A Survey of LGBT Americans." Pew Research Center's Social \& Demographic Trends Project. Accessed April 20. http://www.pewsocialtrends.org/2013/06/13/a-survey-oflgbt-americans/.

Tichenor, Veronica. 2005. “Maintaining Men's Dominance: Negotiating Identity and Power When She Earns More.” Sex Roles 53 (3-4): 191-205. doi:10.1007/s11199-005-5678-2.

Townsend, Nicholas. 2002. "Cultural Contexts of Father Involvement." Handbook of Father Involvement: Multidisciplinary Perspectives, 249-77.

Vandello, Joseph A., Vanessa E. Hettinger, Jennifer K. Bosson, and Jasmine Siddiqi. 2013. "When Equal Isn't Really Equal: The Masculine Dilemma of Seeking Work Flexibility." Journal of Social Issues 69 (2): 303-21. doi:10.1111/josi.12016.

Voydanoff, Patricia. 1988. "Work Role Characteristics, Family Structure Demands, and Work/family Conflict." Journal of Marriage and the Family, 749-61. . 2004. "The Effects of Work Demands and Resources on Work-to-Family Conflict and Facilitation." Journal of Marriage and Family 66 (2): 398-412.

- 2005. "Social Integration, Work-Family Conflict and Facilitation, and Job and Marital Quality." Journal of Marriage and Family 67 (3): 666-79.

Wang, Wendy. 2013. "Breadwinner Moms." Pew Research Center's Social \& Demographic Trends Project. May 29. http://www.pewsocialtrends.org/2013/05/29/breadwinner-moms/.

Weigt, Jill M., and Catherine Richards Solomon. 2008. "Work-family Management among Low-Wage Service Workers and Assistant Professors in the USA: A Comparative Intersectional Analysis." Gender, Work \& Organization 15 (6): 621-49. doi:10.1111/j.1468-0432.2008.00419.x.

West, Candace, and Don H. Zimmerman. 1987. "Doing Gender.” Gender \& Society 1 (2): $125-51$.

Williams, Joan. 2000. Unbending Gender: Why Family and Work Conflict and What to Do about It. Oxford; New York: Oxford University Press.

Williams, Joan C., Mary Blair-Loy, and Jennifer L. Berdahl. 2013. "Cultural Schemas, Social Class, and the Flexibility Stigma: Cultural Schemas and Social Class." Journal of Social Issues 69 (2): 209-34. doi:10.1111/josi.12012.

Williams, Stephen. 2008. "What Is Fatherhood? Searching for the Reflexive Father." Sociology 42 (3): 487-502.

Winslow, Sarah. 2005. "Work-Family Conflict, Gender, and Parenthood, 19771997." Journal of Family Issues 26 (6): 727-55. doi:10.1177/0192513X05277522.

$\mathrm{Xu}, \mathrm{Wu}$, and Ann Leffler. 1992. "Gender and Race Effects on Occupational Prestige, Segregation, and Earnings." Gender \& Society 6 (3): 376-92. doi:10.1177/089124392006003003. 
